\title{
El proceso de urbanización del sector meridional del territorio vascón y la comarca de Tudela (II)
}

\author{
The urbanization process of the southern sector \\ of the Vascones' territory and the current district of Tudela \\ de Navarra (II)
}

JUAN JOSÉ SAYAS ABENGOECHEA

UNED

\begin{abstract}
RESUMEN
Como continuación de un trabajo anterior (ETF(2), 15, 2004) centrado en aspectos del poblamiento en la II Edad del Hierro en la parte meridional del territorio que las fuentes antiguas -especialmente Ptolomeo- atribuyen a los Vascones, se plantean en este trabajo algunas hipótesis sobre los ritmos de organización territorial de las ciuitates citadas en las fuentes para esta zona, sobre el intenso poblamiento de la misma y, especialmente, sobre el momento en que la urbanización a la romana pudo ser una realidad en ella. El análisis se hace partiendo de la evolución histórica de estos territorios desde época republicana y revisando la documentación arqueológica, literaria y numismática disponible al efecto.
\end{abstract}

PALABRAS CLAVE:

Hispania, Vascones, urbanización, conquista, fuentes, República Romana.

\section{ABSTRACT}

As a following investigation on the same area of Hispania (ETF(2), 15, 2004) that, then, discoussed the ancient settlement in the II Iron Age among the south part of the ancient Vascones' territory — known, specially by Ptolomeus - this paper presents some theories about the developing of the urbanization and territorial organization in the ciuitates listed in ancient sources for this zone. Specially, the subject of the moment in which Roman cities were founded in the area and roman urbanization could turn into real changing the aspect of the area are reconsidered from the analysis of the historical evolution of those territories from Republican times by the reinterpretation of the archaeological, literary and numismatic available evidences.

KEYWORDS:

Hispania, Vascones, urbanization, conquest, ancient sources, Roman Republic. 


\section{INTRODUCCIÓN*}

En el primitivo territorio de los vascones el desarrollo del urbanismo y la aparición de la moneda tienen lugar cuando las gentes de esas tierras entran en contacto con los romanos. La situación creada en la zona por efecto de la difusión de la escritura se ha etiquetado con la expresión de la escritura en la frontera ${ }^{1}$. Este fenómeno se añade al hecho de que las tierras del valle medio del Ebro eran ya marco de confluencia y de contacto de elementos culturales de los indoeuropeos, iberos y vascones.

\section{CIUDADES INDÍGENAS CONOCIDAS POR LAS MONEDAS Y LOS TEXTOS LITERARIOS}

1.1. A este respecto las monedas con rótulos en grafía ibérica no sólo proporcionan material lingüístico muy provechoso para conocer a grandes rasgos la situación lingüística de la zona, sino que aportan, subsidiariamente, una información muy interesante para averiguar el desarrollo alcanzado en la zona por el modelo de la ciudad, habida cuenta que las sedes de las cecas suelen coincidir habitualmente con asentamientos de relativa importancia. Incluso algunos investigadores consideran que desde el punto de vista de las sedes de las cecas se ha producido su distribución ordenada dentro de un territorio comarcal, reordenación que supondría, de hecho, una consciente reordenación económica del territorio. Piensan que algunos territorios están articulados conforme a modelo comarcal, en el que se aprecia una jerarquización de las sedes de las cecas: las que acuñan monedas de plata y bronce, las que acuñan únicamente bronce y las ciudades que no disponen de ceca².

\footnotetext{
* Trabajo realizado dentro del marco del proyecto de investigación de la CICYT , BHA2001-1397, concedido al autor.

1 Fco, Beltrán Lloris, «La escritura en la Frontera. Inscripciones y cultura epigráfica en el Valle medio del Ebro" en Roma y el nacimiento de la cultura epigráfica en occidente, Zaragoza, 1995, pp. 169-195.

2 No siempre se está en condiciones de identificar una ceca con una ciudad determinada. A este respecto hay una serie de cecas del denominado grupo vascón que se supone que estaban localizadas en Navarra. Entre ellas se encuentran, entre otras, las cecas de olcairum y, sobre todo, barscunes, que inicia sus emisiones de moneda de plata, se opina, en la segunda mitad del siglo II a. C. y alcanza la época sertoriana. Abarcan, por tanto, un largo período durante el cual no se dispone para las tierras propiamente vasconas de ningún testimonio literario ni arqueológico que hagan suponer que disponían de algún centro urbano. Es posible, por tanto, que los lugares emisores de estas monedas estuviesen situados más al sur, en tierras cercanas al Ebro, donde había varias ciudades.

Conviene señalar, respecto al modelo basado en la jerarquización de las cecas, que en las tierras navarras del interior no se aprecia, en momentos en que esas cecas comienzan a emitir, jerarquización comarcal, que de hecho hubiera supuesto una reordenación económica consciente del territorio. No solo no hay, en esos momentos, centros urbanos en territorio propiamente vascón, sino que están sin identificar los lugares de emisión. Por otra parte, no puede perderse de vista que en la Península hay ciudades importantes que no emitieron moneda por las razones que sea. Además es evidente que las acuñaciones de plata y bronce atendían a necesidades diferentes. Ver al respecto Fco. Beltrán Lloris, «Sobre la función de la moneda ibérica e hispano-romana», Estudios en Homenaje al Dr. A. Beltrán Martínez, Zaragoza, 1986, pp. 889-914
} 
Las excavaciones arqueológicas han constatado en algunas ocasiones la existencia de un poblado, lugar de asiento de la comunidad que posteriormente emitirá moneda indígena. Así, por ejemplo, es muy probable que el pequeño poblado de la Edad del Hierro detectado en el cerro de San Francisco de Calahorra ${ }^{3}$ alcanzase un notable desarrollo urbanístico, un poco antes de la presencia romana en la zona. En cualquier caso, la comunidad existente en el ámbito territorial de ese lugar acuñó moneda de plata y bronce con la leyenda kalakorikos, dando a conocer con ello un lugar y una comunidad indígena autónoma con capacidad para acuñar moneda a partir de la segunda mitad del s. II a. C. También Cascantum (Cascante, Navarra) acuñó por esas fechas moneda de bronce en varias series con la leyenda kaiskata ${ }^{4}$; sin embargo no se dispone de datos arqueológicos ni restos constructivos del asentamiento indígena y son muy pocos los obtenidos a partir del momento en el que Cascantum ${ }^{5}$ se convirtió en civitas romana. También en los aledaños del territorio vascón se encuentran las comunidades indígenas que emitieron moneda con las leyendas iaca ${ }^{6}$ y sekia, esta última a partir de siglo ॥ a. C. ${ }^{7}$.

1.2. Se conoce bastante bien la actividad militar desplegada por los romanos en los aledaños orientales y meridionales del territorio vascón ${ }^{8}$. Las fuentes literarias abundan en episodios que acontecen en esos sectores geográficos desde fechas muy tempranas. La narración de los mismos permiten conocer los nombres de algunas comunidades autónomas, cuyos componentes estaban unidos entre si por nuevos vínculos de índole política, jurídica, económica y cultural, que eran más fuertes que los lazos que las relacionaban con el grupo étnico de procedencia, cualquiera que fuese la vigencia y fortaleza de los mismos. Una de estas comunidades cívicas era Calagurris, en cuyas inmediaciones Manlio Acidinio derrotó a los

${ }^{3}$ Ver U. Espinosa, «Excavaciones en el municipio Calagurris Iulia (campaña 1980)», en Expos. Arq. Calagurritana, Calahorra, 1982, pp. 31-35.

4 Ver A. Domínguez, "Las cecas ibéricas del Valle del Ebro", Estudios III, 1977, p. 139 y 140; Idem, Las cecas ibéricas del Valle del Ebro, Zaragoza, 1979.

${ }_{5}$ Cascantum (Cascante, Navarra) ha proporcionado muy pocos testimonios urbanísticos. En la excavación del año 1970 se sacaron a la luz los restos de una casa de tres habitaciones, provistas de pavimentos de opus signinum y huellas de pinturas en las paredes. Debajo del pavimento se encontraron entre los materiales de relleno fragmentos cerámicos campanienses $A$ y $B$ y restos de ánforas del tipo Dressel 1B. Estos fragmentos cerámicos permiten fechar la construcción de la vivienda, o de la villa, hacia mediados del siglo I a. C. Ver al respecto M. A. Mezquíriz, «Descubrimiento de un pavimento de opus signinum en Cascante (Navarra), en Homenaje a D. José Uranga, Pamplona, 1971, pp. 277-283. Con anterioridad, en el solar de la Bodega Cooperativa de Cascante, se obtuvo una ánfora del tipo Dressel 1B, que puede fecharse en el siglo I a. C.

6 Para las monedas de laca, ver A. Domínguez, Las cecas ibéricas del Valle del Ebro, Zaragoza, 1979, pp.135-138; L. Villaronga, Numismática antigua de Hispania, Barcelona, 1979, p.170.

7 Para las monedas indígenas de sekia, ver A. Domínguez, Las cecas ibéricas del Valle del Ebro, Zaragoza, 1979, pp.157-164; L. Villaronga, Numismática antigua de Hispania, Barcelona, 1979, p.171; J. Untermann, Monumenta Linguarum Hispanicarum, tomo I-I, Wiesbaden, 1975, pp. 250-251

${ }^{8}$ Para el proceso de la conquista, ver J.J. Sayas Abengochea, "Conquista y colonización del Valle del Ebro en época tardo-republicana y Principado», en E. Ortiz de Urbina y J. Santos (eds.) Revisiones de Historia Antigua II: Teoría y práctica del ordenamiento municipal en Hispania, Vitoria-Gasteiz, 1996, pp. 63-82. Ver también, G. Fatás, «Los Pirineos meridionales y la conquista romana", en Lengua y cultura en la Hispania prerromana, Salamanca,1993, pp. 289-316. 
celtíberos en el 188 a. Luego, en esa comarca, unos años después, en el 179-178 a. C., Sempronio Graco fundó una ciudad, a la que dio su nombre, pero que antes se llamaba llurcis, según el enciclopedista Sexto Pompeyo Festo. Y por lo que hace al sector oriental, en tierras posteriormente vasconas, las fuentes literarias describen a Corbio como un oppidum provisto de sólidas defensas. Señalan también que los iacetanos (con lacca como ciudad principal), que solían realizar incursiones contra los pueblos vecinos, fueron derrotados por Catón a comienzos del s. II a. C. ${ }^{9}$.

En definitiva, en los aledaños orientales de la zona considerada, las fuentes mencionan para la primera y segunda mitad del s. II a. C., en razón a diversas circunstancias y motivos, etnónimos tales como sedetanos, suessetanos, celtíberos de distintos grupos, etc.; pero también ciudades concretas como laka, Corbio, Ilurcis, Gracchurris, Calagurris. Además, algunas de esas fuentes permiten captar de una manera general el grado de cohesión y de relación que esas ciudades guardaban con el grupo étnico originario o con el grupo humano que predominaba en el territorio en el que esas ciudades estaban situadas. Corbio, por ejemplo, está claro que estaba manteniendo en esos momentos estrechas relaciones con el pueblo de los suesetanos, hasta el punto que la ciudad y grupo étnico parecen correr la misma suerte: la caída del oppidum de Corbio supone también la decadencia de los suessetanos ${ }^{10}$. Por el contrario, las relaciones del grupo étnico celtíbero que controlaba anteriormente la zona con las comunidades de Calagurris y Gracchurris (cabe suponer lo mismo para Cascantum, aunque no hay evidencia) no existen o fueron muy lasas a juzgar por la independencia con la que actuaron esas ciudades.

\footnotetext{
${ }^{9}$ Las fuentes indican que Catón sometió a sedetanos, ausetanos y «lacetanos». Según R. Knapp, "Cato in Spain, 195/194 B.C.: chronology and geography», en C. Deroux (ed.), Studies in Latin Literature and Roman History II, Bruselas, 1980, p. 43, estas operaciones tuvieron lugar probablemente después de su regreso de la Turdetania. Otros autores como Plutarco, Tito Livio, y Frontino coinciden en la mención de los «lacetanos» y en la colocación de los suesetanos, «lacetanos», ausetanos, etc. como pueblos vecinos. La mención a los «lacetanos», por una parte, y la vecindad señalada, por otra, no se ajustan a los datos proporcionados por otras fuentes. Ver J.J. Sayas Abengochea, "Conquista y colonización del Valle del Ebro..... o. c. pp. 64-65. Para paliar estas dificultades P. Jacob, «Un doublet dans le geographie livienne de I'Espagne antique: les Ausetans de l'Ebre", Kalathos 7-8, 1987-1988, pp. 135-147 recurre a la propuesta de la existencia de dos ramas de ausetanos. Según este autor, una de ellas estaría situada en esta zona del valle del Ebro. Para el problema que presentan las fuentes que hacen alusión al pueblo de los «lacetanos», ver G. Fatás, «Hispania entre Catón y Graco. Algunas precisiones basadas en las fuentes», H. A. 5, 1975, pp. 269 y ss.

10 Con arreglo a la información proporcionada por Tito Livio (XXXIV, 20, 1-9) Corbio fue un oppidum de sólidas defensas. El pretor Terencio Varrón debió de utilizar maquinas de asedio para apoderarse de la ciudad. Una vez capturada, sus habitantes fueron vendidos como esclavos: in suessetanis oppidum Corbionem vineis et operibus expugnavit captivos vendidit. La población del oppidum y el populus de los suessetanos mantuvieron relaciones muy estrechas. La mención de esta ciudad desaparece prácticamente de las fuentes literarias a partir del 184 a. C., aunque Plinio $(I I I, 3,24)$ todavía registra esa región (Oscenses regionis Suessetaniae). En algún momento posterior a la captura de la ciudad el territorio suessetano pasó a ser asignado a los vascones.
} 


\section{LA SITUACIÓN EN TERRITORIO VASCÓN}

\subsection{Punto de partida}

La consecuencia inmediata que se desprende de los acontecimientos mencionados arriba es que los romanos habían alcanzado el territorio de los jacetanos y suesetanos y establecido su dominio en las tierras llanas del valle medio del Ebro en fechas tan tempranas como las de los comienzos del s. II a. C. Sigue siendo, sin embargo, una incógnita qué pasó o qué estaba pasando por esas fechas al otro lado del Ebro, en territorio vascón, en él los investigadores sitúan, en lugares que están todavía por identificar, una serie de cecas que acuñan moneda a mediados del s. II a. C. Y si la cuestión se centrara, dejando a un lado las cuestiones monetales, en el conocimiento del grado de transformación alcanzado en ese territorio vascón en los momentos en los que las comunidades limítrofes son combatidas y controladas por los ejércitos romanos, la respuesta sería negativa. Las fuentes literarias no sólo no mencionan ciudad alguna que pudiera ser calificada de vascona, sino que ni siquiera fuente alguna escrita recoge el etnónimo de vascones para esas fechas.

Pero aunque se carezca lamentablemente de la necesaria información literaria, no resulta, sin embargo, muy difícil hacerse una idea en líneas generales de las transformaciones que comportó la presencia romana en esos territorios, especialmente en lo que se refiere al proceso de urbanización y de reorganización del territorio. Aunque los datos arqueológicos que pudieran servir de guía en la valoración de los cambios operados resultan mas bien escasos, son, no obstante, suficientes en algunos yacimientos para constatar la existencia en los mismos de un poblado indígena ${ }^{11}$, que se transforma posteriormente en núcleo urbano, o para percibir en otros asentamientos de carácter rural la continuidad de lo indígena en lo romano. A pesar de ello, resulta muy difícil valorar, en términos humanos y políticos, el alcance e intensidad de los cambios producidos en todo el territorio considerado, pues el principal modo de inferencia se realiza a partir del cotejo y análisis

11 En el año 1956, se obtuvo, en algunos lugares concretos del casco viejo de Pamplona, un importante lote de fragmentos de cerámicas hechas a mano, y en menor cuantía de cerámica celtibérica. Estos testimonios arqueológicos ponían de manifiesto que un poblado indígena existía en ese lugar desde la Primera Edad del Hierro. Algo similar sucede en Andelos y en Cara, que han proporcionado fragmentos de cerámicas hechas a mano y también celtibéricas. Ver al respecto J.J. Sayas Abengochea, «Transformaciones urbanísticas de las comunidades vasconas», en Indígenas y Romanos en el norte de la Península Ibérica, XI Cursos de verano en San Sebastián, 1993, p. 227 y ss.

Y por lo que hace a la antigua Calahorra, fue encontrado en las excavaciones realizadas en el solar de La Clínica un lote de fragmentos de cerámica hecha a mano, que fueron llevadas a allí por traslado de tierras de algún otro lugar de la ciudad. Pese a que se trata de elementos descontextualizados, estos restos cerámicos ponen de manifiesto que en la Calahorra antigua había un poblado de la Edad del Bronce. Ver U. Espinosa, Calagurris Iulia, Logroño, 1984, p. 17. Por otra parte, las investigaciones arqueológicas realizadas en las Eras de San Martín de Alfaro (Gracchurris) detectan la existencia de un yacimiento que se remontaba a la Primera Edad del Hierro. Ver J. A. Hernández, E. Ariño, J. Núñez, J. M. Martínez, Gracchurris. Conjuntos monumentales en la periferia urbana: puentes, presas ninfeos, Gracchurris 4, Ayuntamiento de Alfaro, Logroño, 1995, p. 53 y ss. 
de los datos de cultura material que resultan más significativos en la percepción de esos cambios. Y en este sentido hay que tener presente que sólo un $20 \%$ de los más de 250 asentamientos rurales romanos registrados en Navarra, casi todos ellos en la zona media y meridional de Navarra, ofrecen materiales de tipo celtibérico unidos a otros romanos ${ }^{12}$. La inmensa mayoría de esos materiales se han obtenido en prospecciones de superficie. Sólo el asentamiento rural de El Castejón de Arguedas, excavado hace más de medio siglo por Blas Taracena, se conoce relativamente bien ${ }^{13}$. A éste se podría añadir el poblado de Cabezo Lobo II en las Bardenas Reales, en razón de los materiales celtíbero-romanos recogidos ${ }^{14}$, y algún otro yacimiento.

\subsection{El paso de territorio conquistado a territorio organizado.}

La etapa de la conquista y sobre todo los conflictos sertorianos son considerados en la historiografía moderna como el marco cronológico en el que se producen los cambios más significativos no sólo en la reordenación del territorio, sino también en la aparición de entidades político-administrativas de carácter local; en otras palabras, la transformación de las tierras vasconas de espacio conquistado o anexionado en espacio organizado con la aparición de civitates acontece en el período indicado. Lo que ocurre es que, debido a los menguados hallazgos de cultura material obtenidos y a los escasos restos constructivos de cierta significación, no es posible conocer la profundidad de los cambios políticos alcanzados en esos primeros momentos, ni trazar inferencias documentadas de las diferencias sociales producidas en el seno de la población, como tampoco constatar la cristalización y desarrollo de las relaciones socio-políticas que ligaron los nuevos oppida de raigambre vascona con los territorios circundantes y con el amplio grupo étnico vascón en cuyo territorio se acrisolaron esas entidades locales indígenas.

En este sentido, es evidente que el punto de partida no era el mismo en las distintas comarcas. Poco o nada se sabe de las relaciones o decisiones al respecto del grupo étnico vascón (en el caso de que tuviese una entidad de carácter unita-

12 La continuidad de la ocupación de algunos lugares y la reorganización del espacio ocupado en otros afecta con exclusividad a los asentamientos situados en la Navarra media y meridional. En estos yacimientos se han obtenido, gracias a excavaciones o prospecciones superficiales, materiales de la Edad del Hierro I o II y materiales romanos. Ver al respecto J. J. Sayas Abengochea, «Transformaciones urbanísticas de las comunidades vasconas o. c. p. 230 y ss.

${ }_{13}$ El asentamiento indígena de Castejón de Arguedas se remonta a la Primera Edad del Hierro. En su fase romana el poblado formaba una pequeña aldea, con casas de planta cuadrada o rectangular. Para la excavación de este asentamiento rural y los materiales encontrados, ver B. Taracena y L. Vázquez de Parga, «Exploración del Castejón de Arguedas», P.V. XI, 1943, pp. 129-159.

14 Para este asentamiento de Las Bardenas, ver los trabajos de M. ${ }^{a}$ L. García García, «La ocupación del territorio navarro en la época romana», CAUN 3, pp. $231-269$, y «El poblamiento en época romana en Navarra: sistemas de distribución y modelos de asentamientos», Isturitz 8, 1997, pp. 75-110, especialmente p. 82. La secuencia celtíbero-romana se establece en razón a los materiales celtíbero-romanos encontrados en superficie. 
rio) con las nuevas comunidades locales vasconas emergentes. Por el contrario, nuestro conocimiento es menos evanescente por lo que se refiere a los territorios orientales y meridionales que más tarde pasarán a formar parte del territorio vascón. Se sabe por las fuentes históricas, como ya hemos visto, que Corbio y Calagurris eran ya oppida con anterioridad a la presencia romana, al contrario que Gracchurris, que era una fundación romana. A su vez, el oppidum de Corbio mantenía estrechas relaciones con el grupo étnico de los suessetanos, mientras que Calagurris era una ciudad que estaba muy desligada políticamente del grupo celtibérico que dominaba la zona y Gracchurris emergía en ella como una ciudad autónoma desvinculada del grupo étnico al que pudiera pertenecer llurcis.

\section{CAMBIOS EN LA COMARCA CONSIDERADA DURANTE LA CONQUISTA Y LOS CONFLICTOS SERTORIANOS}

\subsection{La fundación de Gracurris}

Los datos de las fuentes literarias sobre el origen de Gracchurris, breves y tardíos, se prestan a confusión. Ciertamente el topónimo Gracchurris es una combinación latino-indígena, con un primer elemento que se relaciona con el nombre de T. Sempronio Graco, gobernador de la Citerior durante los años 179-177 a. C., y un segundo elemento - gurris, similar al que se aprecia en el nombre de la vecina $\mathrm{Ca}$ lagurris. Este gobernador combatió no sólo en la Citerior, que tenía encomendada a su cargo y obtuvo por su éxitos en ella el triunfo de celtiberis Hispaneisque, sino también en la Ulterior, donde fundó la ciudad de lliturgi (Menjíbar, Jaén), como recuerda un epígrafe dado a conocer en el 1961 y que algunos investigadores consideran falso $\mathrm{O}^{15}$. No se puede poner en duda, porque así lo ponen de manifiesto las fuentes históricas, que Graco combatió en la Ulterior, pudiendo tener con ello la oportunidad de fundar en aquella provincia la ciudad de lliturgi, que ofrece un segundo elemento compuesto -urgi, -urci, frecuente en topónimos meridionales de la Península ${ }^{16}$. Y, por otra parte, también es innegable que en Periochae, 41, se dice expresamente que Graco fundó Gracchurris, y el propio topónimo es una prueba irrefutable de la estrecha relación con Graco. Es la información Gracchurris antea Ilurcis nominabatur ${ }^{17}$, proporcionada por Sexto Pompeyo Festo, la que da pie a

${ }^{15}$ Está recogida en Historia Antiqua Epigraphica, 12-16, 1961-1962, n. 2079 : Ti.Sempronio Graccho/deductori/populus iliturgitanus. R. Wiegels, «lliturgi und der deductor Ti. Sempronius Gracchus», MM 23, 1982, pp. 153-221 y 518-526, hace un amplio estudio de esta inscripción. Piensa que fue realizada en el s. II d. C. (posiblemente en época de Tiberio, por los caracteres paleográficos), con un contenido histórico supuestamente falso, pues piensa que Graco no fundó lliturgi. Pero es evidente que Graco actuó militarmente tanto en la provincia Citerior que tenía encomendada, como en la Ulterior. Con arreglo a las circunstancias y a los testimonios de la época de Graco, nada impedía que este personaje gozara de atribuciones para fundar una ciudad en la provincia no encomendada a su cargo.

${ }_{16}$ Ver al respecto F. Villar, Indoeuropeos y no indoeuropeos en la Hispania prerromana, Salamanca, 2000 , p. 260 y ss.

17 De la obra de Tito Livio se hicieron resúmenes (Periochae) durante los siglos III-IV d. C., con fines didácticos. La Per. 41 señala: Tib. Sempronius Gracchus procos. Celtiberos victos in deditionem accepit 
confusión cuando se la relaciona y confronta, como es razonable, con el epígrafe y la Per. 41. Es muy posible que este autor resumiera y confundiera en un mismo relato las dos fundaciones de Graco: la lliturgi andaluza (registrada en las fuentes griegas como Ilourgis, Ilourgia) y la Gracchurris riojana, utilizando el nombre de la andaluza como antiguo nombre (Ilurcis) de Gracchurris. Recuérdese, como ya hemos indicado, que el final -urgi, -urci de los topónimos es característico de los nombres de lugar de la Hispania meridional, e llurcis, por supuesto, lleva ese final.

La ciudad de Gracchurris no fue la fundación de una colonia ni tampoco fue, quizás, resultado de una deductio militar o civil, o ambas cosas a la vez, como se pretende ${ }^{18}$. Incluso se llega a suponer que Gracchurris fuese, quizás, desde su creación, un municipio de derecho latino, en razón a la pretensión de que pudo fundarse con nativos y socii itálicos, ex-soldados. Es cierto que en situaciones similares de mixtura poblacional el municipio de derecho latino se revela como el marco jurídico más apropiado para regular la vida en comunidad de municipes con ciudadanía diferente ${ }^{19}$. Pero diversos elementos a considerar, como la entidad lingüística del topónimo llurcis, el elemento - gurris de Gracchurris y la leyenda incompleta l.u.e.i.ka.r- de un fragmento cerámico hallado en Alfaro, hacen suponer suficientemente que la ciudad de Gracchurris se fundó con nativos, al menos en parte, posiblemente vascones ${ }^{20}$.

Es evidente que el término constituit utilizado en la Periochae 41 implica ciertamente la configuración en las Eras de San Martín (Alfaro, La Rioja) de una nueva comunidad, acarreando con ello, necesariamente, no sólo el establecimiento y ordenación del territorio de la nueva comunidad (incluyera o no incluyera éste, total o parcialmente, el territorio de la antigua Ilurcis), sino también la distribución y

monimentumque operum suorum Gracchurrim oppidum in Hispania constituit. Por otro lado, Sexto Pompeyo Festo, que vivió en la segunda mitad del siglo II d. C., realizó una obra en 20 libros que constituye una especie de diccionario enciclopédico. En De verborum sign. Cum Pauli Epit., 97, dice respecto a la voz Gracchurris: ubs Iberiae regionis, dicta a Graccho Sempronio, quae antea Ilurcis nominabatur.

18 Algunos investigadores, como A. García y Bellido y J. M. B Blázquez, consideran que la ciudad de Grachurris comenzó su andadura con una doble población, la indígena peregrina y la itálica. Ver sus opiniones en «Las colonias romanas de Hispania», An. Hist. Der. Esp. 24, 1959, pp. 448-9, y «Los vascos y sus vecinos en las fuentes literarias griegas y romanas de la Antigüedad», Problemas de la Prehistoria y de la Etnología Vascas, Pamplona, 1966, pp. 192 y ss respectivamente. Ver también P. Le Roux, «Armées et promotion urbaine en Hispaniae sous l'Empire, en A. Rodríguez Colmenero (coord.), Los orígenes de la ciudad en el noroeste hispánico. Actas del congreso internacional (Lugo, 15-18 mayo 1996), Lugo: Ministerio de Educación y Ciencia, 1998, pp. 202-3.

19 Para el estatuto de municipio de derecho latino de esta comunidad, ver J. J. Sayas Abengochea, «El municipio de Vasconia en el mundo antiguo», en IV Symposium. El municipio foral u actual en los territorios de Vasconia (Donostia-San Sebastián 9-XII-2004), en prensa.

20 Para el fragmento cerámico con inscripción incompleta hallado en Alfaro, ver J. A. Hernández Vera y J. Núñez Marcén, «Un nuevo antropónimo indígena sobre cerámica, procedente de Gracchurris», Veleia 6, 1989, pp. 207-214. Para los comentarios lingüísticos de esta inscripción, ver J. Gorrochategui, «Los Pirineos entre Galia e Hispania: las lenguas», Veleia 12 , 1995, p. 190. R. López Melero, « ¿Gracchurris fundación celtibérica?», Veleia 4, 1987, pp. 171-177 defiende la hipótesis de que la fundación de Gracchurris pudo realizarse con gentes vasconas, con la finalidad de que esta ciudad estabilizara la zona celtíbera recientemente pacificada y para que desde ella se asegurasen las rutas que llevaban al norte peninsular y a la Meseta. 
asignación de tierras a los nuevos miembros de la ciudad y a los antiguos pobladores de llurcis, en el caso de que formasen parte de la nueva comunidad y no se tratase en realidad de la confusión anteriormente apuntada.

Es posible que en una fecha tan temprana como la del 179-178 a. C. en la que se fundó la ciudad, y tratándose como parece que se trata de una ciudad indígena, los romanos no utilizasen en la ordenación del territorio y en la asignación de tierras y supuesta confirmación de propiedades o asignación de nuevas a los ilurcitanos, la parafernalia de la centuriación. No obstante, algunos investigadores ${ }^{21}$ han encontrado en las cercanías de Alfaro indicios de una posible centuriación, que no está avalada por testimonios literarios o epigráficos, sino por elementos de entidad relativa ${ }^{22}$, que, en cualquier caso, no disponen de virtualidad operativa suficiente como para hacer retrotraer esa supuesta centuriación a las fechas fundacionales de la ciudad. Sería más razonable intentar situar la posible centuriación en cualquier momento posterior e importante de la trayectoria político-administrativa de la ciudad.

\subsection{Destrucciones y transformaciones en época sertoriana.}

Los conflictos sertorianos afectaron profundamente a la tierras del valle medio del Ebro. Algunas ciudades intensificaron sus emisiones monetales con la intención, posiblemente, de poder satisfacer las soldadas de los miembros de ambos ejércitos. Otras cambiaron su actitud de receptoras pasivas de la cultura y modos de vida romanos por una participación política y militar activa, poniéndose al lado de Sertorio, el caudillo carismático, o inclinándose por Pompeyo, representante de la legitimidad constitucional ${ }^{23}$. De esta manera, la zona del valle medio del Ebro se vio sometida a continuos sobresaltos y destrucciones, como consecuencia de las

21 Ver al respecto J. Gómez Pantoja, «Sobre un posible catastro romano en el límite navarro-riojano», Príncipe de Viana 148-149, 1977, pp. 423-433, y «Vestigios de una posible centuriatio romana en las cercanías de Alfaro (Logroño)», CNA 15, Zaragoza, 1979, pp. 929-936. Los mismos términos utilizados en los títulos de los trabajos anuncian que se trata de una propuesta hipotética.

22 E. Ariño en un trabajo sobre las centuriaciones en La Rioja titulado Centuriaciones romanas en el Valle Medio del Ebro, Logroño, 1986, pp. 25-32, especifica la entidad relativa de los elementos de valoración utilizados, hasta donde lo permite una documentación un tanto evanescente: una red de caminos coincidentes con el módulo romano de 20 actus, concordando los límites municipales con la dirección de los caminos; la presencia de restos arqueológicos, como por ejemplo dos puentes situados a distancia de dos centurias; una toponimia de escurridiza utilización y un estado de conservación de la centuriación bastante buena en su parte central. Por otra parte, en un volumen monográfico de la revista Gracchurris, J. A., Hernández, E. Ariño, J. Núñez y J. Martínez, Gracchurris. Conjuntos monumentales en la periferia urbana: puentes, presas ninfeos, n. ${ }^{4}$ de Gracchurris, Logroño, 1995, pp.237-250, ponen en relación estos dos conjuntos monumentales con los catastros, las vías y los asentamientos rurales.

${ }_{23}$ Para el desarrollo del los conflictos sertorianos en la zona del valle medio del Ebro y sobre el papel que las clientelas hispanas desempeñan en los mismos, ver N. Dupré, «La place de la vallée de I'Ebre dans I'Espagne romaine. Recherches de géographie historique», MCV. 9, 1973, pp. 133-175; J. M. Roddaz, "Guerres civiles et romanisation dans la vallée de l'Ebre», REA., 1986, pp. 317-338; J. J. Sayas Abengochea, «Indoeuropeos y vascones en territorio vascón», Studia Palaeohispanica. Actas del IV coloquio sobre lenguas y culturas paleohispánicas, Victoriaco Vasconum, 1987, pp. 409-410. 
acciones desencadenadas por los bandos contendientes. La desaparición del asentamiento de Valdetaus (a $3 \mathrm{kms}$. de Tauste, Zaragoza), que se sitúa en la primera mitad del s. I a. C., se pone, lógicamente, en relación con los conflictos sertorianos ${ }^{24}$. Para el control de las comunidades de esta zona del valle medio del Ebro, la ciudad amurallada de Contrebia Leukade se convirtió en pieza clave en el sistema táctico ideado por las tropas sertorianas ${ }^{25}$. Como consecuencia de ello, las ciudades de Gracchurris y Cascantum fueron saqueadas y sus cosechas arrasadas para que el ejército sertoriano pudieran remontar sin problemas a través del ager Vasconum la orilla derecha del Ebro hasta llegar a territorio berón. Por el contrario, Pompeyo con sus tropas se retiró, frumenti causa, al norte del Ebro, en territorio vascón, donde los poblados indígenas de Pompaelo, Andelos y Cara se transforman en oppida, merced a los impulsos recibidos posiblemente por las tropas que estaban allí en invernada. Mas tarde, después de varios reveses de las tropas sertorianas, el ejército pompeyano tomó la ciudad de Calagurris, masacró su población y destruyó la ciudad ${ }^{26}$.

En otro orden de cosas, los conflictos sertorianos, con los asaltos, saqueos y destrucciones a los que dieron lugar, impulsaron desplazamientos incontrolados de población, causantes, con mucha probabilidad, de la compleja situación lingüística vivida en algunas comarcas reducidas como la de Andelos ${ }^{27}$. Las convulsiones provocadas por estos conflictos proporcionan la oportunidad histórica adecuada para

${ }^{24}$ Ver al respecto M.P. Lanzarote Subías y M.A. Magallón, «El yacimiento indígena-romano de Valdetaus», Suessetania 11, Ejea, 1990, pp. 74-81, especialmente p.80.

${ }_{25}$ Contrebia es una ciudad indígena que Tito Livio (frag. 91) cita acompañada con el sobrenombre Leucade. Sobre esta ciudad y su identificación, ver B. Taracena, «Noticia de un despoblado junto a Cervera del Río Alhama, AEAA, 1929, p. 137 y ss.; J. A. Hernández Vera, las ruinas de Inestrillas; estudio arqueológico (Aguilar del Río Alhama, La Rioja), Logroño, 1982, p. 221 y ss.; J. A. Hernández Vera, J.M., Martínez Torrecilla, «Contrebia Leukade: consideraciones sobre material cerámico», Estrato, 6, pp. 25-30.

26 Orosio $(5,23,14)$ atribuye a Afranio, en quien Pompeyo había delegado el mando, el asedio y destrucción de la ciudad, que pereció ultima caede et incendio. Las Actas Triunfales recuerdan la celebración del triunfo de Afranio en Roma: Afranius A. f. pro consule(?) ex Hispania(?). A. Degrassi (ed.), Inscriptiones Italiae XIII.I: Fasti Consulares et Triunphales, Roma, 1949, p. 565, considera que este triunfo tuvo lugar en el año 70 a.C. Ver al respecto, M. Malavolta, «La carriera de L. Afranio (Cos. 60 a. C.)», Miscellanea Greca e Romana V, 1977, pp. 251-303, especialmente pp. 255-261. Con argumentos de mayor peso, Ch. Conrad, «Afranius Imperator», HA VIII, 1978, pp. 67-76, fecha el triunfo de Afranio en el año 67 a. C . y propone la siguiente reconstrucción de la información originaria de las Actas: L. Afranius A. f. n. pro. cos. a. DCLXXXVI ex Hispania de Calaguritaneis Celtibereis.

27 El poblado prerromano de Andelo ofrece los usuales materiales de las gentes asentadas en suelo navarro durante la Edad del Hierro. Sin embargo, el topónimo Andelo, al igual que el de Pompaelo, presenta un segundo elemento de compuesto -elo, antecedente del vasco iri, irun, «ciudad», como señala J. Gorrochategui, «Los Pirineos entre Galia e Hispania: las lenguas», Veleia 12, 1995, p. 221. Incluso se llega a proponer un radical *And-, que se documenta en formas aquitanas como And-ere y And-ossus, con el significado de «grande». Andelo= ciudad grande».

En este asentamiento, configurado ya como ciudad romana, se encontró una inscripción musivaria de grafía y lengua ibérica, que formaba parte del pavimento de una casa datada en el siglo I. a. C. Por factura y contenido, la inscripción era semejante a otra hallada en el término de La Caridad, Caminreal (Teruel). Algunos de los nombres que aparecen en estas inscripciones tienen paralelos en la nómina celtibérica. El contexto lingüístico de la comarca de Andelo es complejo, como se puede apreciar: hay antropónimos ibéricos, como el de Calpurnia Urchatetelli, pronunciado « a la vasca»; indoeuropeos, como Ambatus, y teónimos de raigambre vascona, como Larrahi. 
que algunas ciudades que no eran inicialmente vasconas pasasen a serlo, aunque hay que tener muy presente a este respecto de que ninguna fuente literaria otorga el denominativo de vascona a ninguna ciudad en esa época ${ }^{28}$. Si se deja a un lado el registro del etnónimo vascón en la Ora Marítima de Rufo Festo Avieno y en el poema Punica de Silio Itálico —difícilmente aceptable el uso de tal denominación étnica para épocas anteriores a su conquista ${ }^{29}$ - y la expresión ager Vasconum registrada por Tito Livio (frag. 91) con ocasión de la guerra sertoriana, es preciso esperar a la época augústea, por extraño que parezca, para que Estrabón (64 a.C.-c. 24 d.C.) sea el primer autor que califique de vasconas a tres ciudades concretas: Pompeiopolis, Oiasouna y Calagurris ${ }^{30}$. Esta época augústea representa también para los arqueólogos un período fructífero en la constitución de nuevas civitates en el territorio norteño de Navarra: la de los Aracelitani, la de los Ilumberritani e Iturissa.

\section{LA NÓMINA DE CIUDADES VASCONAS}

\subsection{Ciudades mencionadas por Plinio sin indicación del grupo étnico}

Entre las ciudades del convento cesaraugustano, Plinio el Viejo (23/24 -79 d. C.) registra una serie de ciudades (populi es el término utilizado en esta ocasión por Plinio) que van acompañadas de la mención del estatuto jurídico correspondiente. En conformidad con el pasaje pliniano, los Calagurritani (Calahorra) cons-

28 Sobre la cuestión del expansionismo vascón, ver mis trabajos «De historiae Vasconiae rebus controversis» en Actas del Primer Congreso General de Historia de Navarra, Anejo 6 de Príncipe de Viana, Ponencias, Pamplona, 1987, pp. 89-124, y «Algunas consideraciones en torno a la vascona Alavona», Homenaje al Profesor Presedo, Sevilla, 1994, pp. 297-304.

29 Para las referencias de Rufo Festo Avieno y de Silio Itálico alusivas a los vascones, ver J. J. Sayas Abengochea, "Cuestiones relacionadas con la etnia histórica de los Vascones», en Los Pueblos prerromanos del Norte de Hispania. Una transición cultural como debate histórico, Pamplona, 1998, p. 99 y pp. 109-112

30 Estrabón (III, 4, 10) es el primero en calificar de vasconas las comunidades concretas de Calagurris, Pompeiopolis y Oiasouna. Para una valoración del conjunto de las transformaciones urbanísticas experimentadas en algunos poblados, ver mis trabajos «Transformaciones urbanísticas de las comunidades vascones", en J. Santos, (ed), Indígenas y romanos en el Norte de la Península Ibérica. XI Cursos de Verano de la Universidad del País Vasco, San Sebastián, 1993, pp. 227-256, y «Conquista y colonización del valle Medio del Ebro en época tardo republicana y Principado», en E. Ortiz de Urbina y J. Santos, (eds.), Revisiones de Historia Antigua II: Teoría y práctica del ordenamiento municipal en Hispania, Vitoria-Gasteiz, 1996, pp. 63-82.

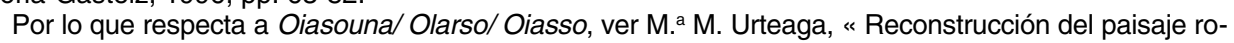
mano en Guipúzcoa: Arqueología e Historia», VI Jornadas sobre la Antigüedad, 1999, pp. 24-31, especialmente p. 28, donde expresa la opinión de que los materiales recuperados en Oiasso presuponen ámbitos de vida plenamente urbanos y plenamente romanos desde el $50 \mathrm{~d}$. C.

Por lo que respecta a las comunidades de los iturisanos, de los aracellitanos y de los ilumberritanos, estas dos últimas ciudades están mencionadas por Plinio (nat. III, 24) como estipendarias. Es posible que la primera coincida con la ciudad que aparece situada en el Itinerario Antoniniano entre Alba y Alantone; la segunda, a su vez, ocupaba un lugar importante en la denominada Vía de Las Cinco Villas. Sobre la comunidad de Iturissa, ciudad no mencionada por Plinio, ver AA.VV., «Necrópolis y poblado de época romana en Espinal (Navarra)», TAN 13, 1997-1998, pp. 75-134. 
tituían un municipio de derecho romano; los Cascantenses (Cascante), los Gracchurritani (Eras de San Martín, Alfaro, La Rioja) y Ergavicenses eran municipios de derecho latino viejo (ius Latinorum veterum); los Tarracenses (probablemente en la comarca de Sádaba, Zaragoza) formaban una comunidad federada; y los AndeIonenses, Aracelitanos, Carenses, Iluberitani, laccetani, Pompelonenses y Segienses (Ejea de los Caballeros) retenían la condición de ciudades estipendiarias sometidas a tributación. No recoge en esta nónima la ciudad Oiarso, aunque la cita en otro pasaje, ni registra, consiguientemente, el estatuto que tenía. Tampoco lo hace con Alauona, una ciudad antigua que acuñó moneda indígena, ni con la ciudad de Iturissa.

Todas estas ciudades están mencionadas sin especificar el grupo étnico de pertenencia. Pero es evidente que aunque Plinio no señale esta circunstancia, en el pasaje aludido concurrían ciudades que se hallaban en tres situaciones diversas con relación a los vascones. Están, por un lado, las ciudades que ya Estrabón calificó, en su momento, de vasconas; concurren, por otro, ciudades de las que sabemos de forma fehaciente que estaban localizadas en territorio vascón y finalmente se encuentran aquellas otras que, sin ser vasconas inicialmente, pasaron a serlo en algún momento ${ }^{31}$.

\subsection{Ciudades vasconas en la obra Geographiké Hyphégesis de Ptolomeo}

Ptolomeo en su Geographiké Hyphégesis, una obra en ocho libros que constituye una especie de catálogo de ciudades del mundo, proporciona una amplia lista de ciudades, calificadas de vasconas ${ }^{32}$, que están registradas con sus coorde-

31 Plinio recoge los populi (comunidades cívicas) que concurren en el convento cesaraugustano, sin indicación de la etnia de pertenencia. Sólo los casos de Caesaraugusta, Osca e llerda van acompañados de complementos identificadores de carácter territorial y social, como regio y gens respectivamente. El pasaje de Plinio, N. H. III. 3. 24 dice: Caesaraugusta colonia, immunis, amne Hibero adfusa, ubi oppidum vocabatur Salduba, regionis Edetana, recepit populos $L$, ex his civium romanorum Bilbilitanos, Celsenses ex colonia, Calagurritanos qui Nasici cognominantur; llerdenses Surdaonum gentis iuxta quos Sicoris fluvius, Oscenses regionis Suessetaniae, Turiassonenses; Latinorum veterum Cascantenses, Ergavicenses, Graccurritanos, Leonicenses, Osicerdenses; foederatos Tarracenses; stipendiarios Arcobrigenses, Andelonenses, Aracelitanos, Bursaonenses, Calagurritanos qui Fibularenses cognominantur, Complutenses, Carenses, Cincienses, Cortonenses, Damanitanos, Ispallenses, Ilursenses, Iluberitanos, lacetanos, Libienses, Pompelonenses, Segienses. Merced a este pasaje se conoce el status jurídico de ciudades que por Estrabón sabemos que ya eran vasconas en fechas anteriores al momento en el que Plinio redactó su obra: Calagurritani municipio de derecho romano, Pompelonenses ciudad estipendiaria (en la nómina de Plinio no se menciona la ciudad de Oiasouna que Estrabón consideraba vascona). En esta lista hay ciudades que se hallaban situadas en territorio vascón: los estipendiarios $A n-$ delonenses, Aracelitani, Carenses e lluberitani y posiblemente también los foederati Tarracenses (Plinio no menciona la ciudad de Iturissa). Otras ciudades mencionadas por Plinio pasaron a ser asignadas a los vascones, posiblemente en diversos momentos históricos: los municipios de derecho latino viejo de los Cascantenses, Gracchurritani y de los Ergavicenses (caso de que esta comunidad sea la Ergavica mencionada por Ptolomeo, cosa que no parece probable), y los estipendiarios lacetani y Segienses. Allavona no está recogida en esta lista de Plinio.

32 Ptolomeo (II, 6, 10-11) alude a los vascones y se refiere a la ciudad de Oeasso, que estaría situada a $15 .^{\circ}, 10^{\prime}$ y $45 .^{\circ}, 05^{\prime}$ de longitud y latitud respectivamente, y al promontorio Oeasso. ubicado a su vez 
nadas de longitud y latitud. Costaría mucho creer que algunas de estas ciudades pudieran pasar como vasconas, si no lo dijese expresamente este autor. No deja de sorprender que sea vascona Allavona (Alagón), situada a $25 \mathrm{kms}$. de Zaragoza, y no lo sea, por ejemplo, Manlia o la mansio Belsio, identificadas hipotéticamente y por distintas razones con Mallén (donde hay restos de una ciudad indígena), que linda con tierras navarras.

Como pertenecientes al ethnos de los vascones Ptolomeo registra dieciséis ciudades: Oiasso, Iturissa, Pompelo, Andelos, Bitouris, Kornonion, Ergavica, Nemantourisa, Tarraga, lakka, Setia, Grakourris, Kalagorica, Kaskanton, Mouskaria y Alavona. Para algunas de estas ciudades, esta indicación de vasconas es la única alusión que se posee. Esta única mención no sólo presenta un problema metodológico grave en relación al grado de fiabilidad y veracidad que puede ofrecer un testimonio único no susceptible de ser confrontado y comparado con otros documentos, sino que, además, resulta muy difícil identificar la fuente o fuentes de información que Ptolomeo ha podido tomar como referencia y sus épocas correspondientes. Con esto no se quiere decir que Ptolomeo haya manipulado o recreado esa información, ni que ésta deba desecharse por ser testimonio único (si se aplicara esta rigurosa exigencia metodológica de forma mecánica las lagunas en el conocimiento de la historia regional antigua serían numerosas), sino que no estamos en condiciones de contrastarla y confirmarla en todos sus aspectos con otros testimonios.

Por otra parte, hay que tener presente que en la época en la que escribió Ptolomeo (vivió c. 90 d. C. hasta c. 168 d. C.) la distribución de la Península por ciudades y etnias de pertenencia tenía poco sentido. El grado de romanización alcanzado era muy grande y la mayoría de las ciudades estaban ya plenamente integradas en los sistemas político-administrativos romanos. Perduraba, no obstante, cierta propensión a seguir manteniendo por inercia el empleo de denominaciones de carácter étnico. Una inscripción encontrada en Roma ${ }^{33}$, que pudiera datarse en el s. II d. C., indica que Cayo Mocconio Vero realizó un censo a XXIII(I) civitatium Vasconum et Vardul(lo)rum, sin especificar cuantas de ellas eran vas-

a $15 .^{\circ}, 10$ y a $45 .^{\circ}, 50$. En otro pasaje $(I I, 6,66)$ menciona muchas ciudades vasconas con sus coordenadas de longitud y latitud : Iturissa (15. $\left.{ }^{\circ} 25^{\prime} / 43 .{ }^{\circ} 55^{\prime}\right)$, Pompelon $\left(15 .{ }^{\circ} 00^{\prime} / 43 .{ }^{\circ} 45^{\prime}\right)$, Bituris $\left(15 .{ }^{\circ} 30^{\prime} / 43 .{ }^{\circ} 45^{\prime}\right)$, Andelos (15. $\left.{ }^{\circ} 00 / 43 .{ }^{\circ} 30^{\prime}\right)$, Nemanturista $\left(15 .{ }^{\circ} 35^{\prime} / 43 .{ }^{\circ} 25^{\prime}\right)$, Curnonium (14. $\left..^{\circ} 50^{\prime} / 43 .{ }^{\circ} 15^{\prime}\right)$, lacca $\left(15 .{ }^{\circ} 30^{\prime} / 43 .{ }^{\circ} 15^{\prime}\right)$, Gracuris $\left(15 .{ }^{\circ} 00^{\prime} / 43 .{ }^{\circ} 00^{\prime}\right)$, Calagorica $\left(14 .{ }^{\circ} 40^{\prime} / 42 .{ }^{\circ} 55^{\prime}\right)$, Cascantum $\left(15 .{ }^{\circ} 00^{\prime} / 42 .{ }^{\circ} 45^{\prime}\right)$, Ergavica $\left(14 .{ }^{\circ} 30^{\prime} / 42 .{ }^{\circ} 35^{\prime}\right)$, Tarraga $\left(14 .{ }^{\circ} 45^{\prime} / 42 .{ }^{\circ} 30^{\prime}\right)$, Muskaria $\left(14 .{ }^{\circ} 20^{\prime}\left(42 .{ }^{\circ} 25^{\prime}\right)\right.$, Setia $\left(14 .{ }^{\circ} 40^{\prime} / 42 .{ }^{\circ} 15^{\prime}\right)$, Alavona $\left(14 .{ }^{\circ} 40^{\prime} / 41 .{ }^{\circ} 55^{\prime}\right)$. Silencia algunas otras que Plinio menciona y que se encontraban en territorio vascón: la ciudad de los Carenses (Santacara,Navarra),la ciudad de los Aracelitani (¿Huarte-Araquil? ¿Despoblado de Araciel?, Navarra) y la ciudad de los Iluberitani (Lumbier, Navarra).

${ }_{33}$ La inscripción (CIL,VI,1463), encontrada en Roma, reza así: C. Mocconio/C.F./ Ver(o)/ praetori, legato pro (pr)/ provinciae Achaiae t(r. pl.)/q. urbano III vir. capit(ali) tribuno laticlavio I(eg.)/ VII gemin, at census accipi(en)dos civitatium XXIII(I)/Vasconum et Vardul(Iu)orum/ vixit annis XXXVI/ ex testamento. En su estudio sobre Plinio, D. Detlefsen ya mencionó esta inscripción, D. Detlefsen, «Die geographie der tarraconensichen Provinz bei Plinius (NH, III, 18-30.76-79; IV, 110-112)», Philologus 32, 1873, p. 643. La recoge también, G. Alföldy, Fasti Hispanienses, Wiesbaden, 1969, pp.128-129. La inscripción no aporta fechas concretas. Por indicios indirectos, un tanto imprecisos, pudiera situarse en el s. Il d. C. 
conas y cuantas várdulas. Se ha prestado cierta atención al hecho de que la cifra de 24 ciudades de la inscripción es, curiosamente, la misma que resultaría de la suma de ciudades várdulas y vasconas mencionadas en las tablas de Ptolomeo: ocho ciudades várdulas (Ptol., II, 6,9; II,6,10) y dieciséis vasconas (Ptol., II,6,10-11). Pero se trata de una mera coincidencia. En este sentido, la inscripción no verifica ni confirma la información ptolomaica, ni viceversa. Ptolomeo, por ejemplo, no recoge ni menciona las ciudades vasconas de los Aracelitani, de los Carenses y de los Iluberitani, perfectamente conocidas por otras fuentes, y que unidas a las registradas por él aumentarían la lista.

Por otra parte, el hecho de que Cayo Mocconio haya realizado el censo de un conjunto de ciudades várdulas y vasconas - no de todas - no hace suponer que el territorio de los várdulos y vascones constituyera para determinados efectos ${ }^{34}$, de forma coyuntural o permanente, una unidad administrativa, que estaría a caballo entre dos unidades administrativas conventuales diferentes.

\section{DENSIDAD DE CIUDADES EN LA ZONA CONSIDERADA}

\subsection{En tierras de la orilla derecha del Ebro}

5.1.1. Manlia/Belsio. En tierras de la orilla derecha del Ebro, en las que ya había un conjunto de ciudades correctamente identificadas, las excavaciones ar-

34 El censo de 24 ciudades vasconas y várdulas que Cayo Mocconio Vero realizó, no se extendió a todas las ciudades pertenecientes a esas dos etnias. Se ha llamado la atención sobre el hecho de que el número de 24 ciudades recogido por la inscripción es el mismo que resultaría de la suma de las ciudades várdulas (ocho) y vasconas (dieciséis) mencionadas por Ptolomeo ( Ptol. II, 6,10 y II,6,65 para las ciudades várdulas y II, 6,10 y II, 6, 66 para las vasconas). Pero el hecho es que la inscripción no especifica la proporción concreta de ciudades vasconas y várdulas que forman parte del cómputo global de 24 ciudades. Por otra parte, Ptolomeo, en el caso concreto de la etnia de los vascones, silencia los nombres de las ciudades de los Carenses, de los Iluberitani y de los Aracelitani, conocidas por otras fuentes. Es evidente, por tanto, que la cifra de ciudades vasconas era superior a la registrada por Ptolomeo. Se trataría, por tanto, de una mera coincidencia.

Por otra parte, los datos generales e imprecisos de esta inscripción no proporcionan ninguna base segura para suponer que el territorio de los várdulos y vascones constituía una unidad administrativa a determinados efectos. Los censos, que tenían como objeto realizar una revisión periódica de los ciudadanos y propiedades con vistas a las obligaciones civiles, militares y tributarias de los ciudadanos, eran, generalmente, de carácter local y provincial. El censo local lo realizaban cada cinco años los magistrados denominados quinquenales. El provincial tenía como material básico de valoración y reconsideraba los datos proporcionados por los censos municipales. No era infrecuente, sin embargo, que la provincia, a efectos censuales, se dividiese en distritos menores, como, por ejemplo, los conventos. Pero en el censo considerado, lo mismo que en la supuesta entidad administrativa várdulo-vascona, estarían implicadas dos entidades políticas distintas consagradas por la administración y por el uso: el conventus Cluniensis, al que pertenecen los várdulos, y el conventus Caesaraugustanus, al que concurren los vascones. La actuación de $\mathrm{C}$. Mocconio Vero apunta más bien a un motivo coyuntural y no a una actividad emergente de un organismo administrativo permanente que englobase a vascones y várdulos: por las razones que fuere, era necesario hacer ese censo a esas veinticuatro ciudades várdulas y vasconas, y nada más que a esas, aunque esas dos etnias juntas reunieran un número mayor de ciudades. Sobre estas cuestiones, ver J. J. Sayas Abengochea, «Ad census accipiendos de ciudades vasconas y várdulas y la legatio censualis de un pamplonés», Espacio, Tiempo y Forma, serie II, 2, 1989, pp. 137-152. 
queológicas han constatado la existencia de objetos y de restos arquitectónicos que proporcionan elementos de apoyo a la sugerencia de que había, además, otras ciudades en la zona en cuestión. Así, en la parte oriental de esta zona, en el cerrete denominado el Convento, situado a poco más de un km. de Mallén (Zaragoza) y conocido anteriormente por los materiales recogidos en superficie, las excavaciones realizadas detectaron la presencia de un poblado de la Edad del Hierro (similar al muy próximo de Cortes de Navarra) que enlazaba con la época celtibérica y continuaba en la romana. Las construcciones detectadas y la mayor parte de los materiales obtenidos, con final en el siglo III d. C., corresponden a época imperial ${ }^{35}$. El elemento decisivo que lleva a la aceptación de que estos restos corresponden a una ciudad indígena no es esencialmente arqueológico. Se basa, fundamentalmente, en la hipotética identificación de Manlia con Mallén ${ }^{36}$, efectuada por razones homofónicas. Por otra parte, Mallén es el lugar en el que se suele situar la mansio Balsione, en razón a las distancias indicadas por el Itinerario de Antonino.

5.1.2. Bacadae Aracellitani. En la parte occidental de la zona indicada, no lejos del territorio ocupado por Gracchurris (Alfaro, La Rioja), teniendo en cuenta el amplio margen que para una propuesta de este tipo proporcionan datos literarios y arqueológicos poco específicos al respecto, algunos investigadores proponen la existencia de algún otro asentamiento urbano en esta zona, ya de suyo muy congestionada. Como ya hemos indicado, no puede perderse de vista el hecho de que algunos investigadores consideran que el territorio de Gracchurris fue objeto de una centuriación que se extendería hasta los asentamientos del Montecillo (Castejón, Navarra) y los de Mérida y la Torrecilla (Corella, Navarra). Sin embargo, los asentamientos del término municipal de Corella y de Castejón de Navarra resultan fundamentales para otros investigadores cuando desarrollan y analizan la cuestión abierta y debatida de la probable identificación del despoblado de Araciel, junto a

35 Para las excavaciones de el Convento de Mallén y la secuencia cronológica y cultural de ese asentamiento, ver J. A. Paz y J. L. Royo, «Novedades cerámicas sobre El Convento, Mallén (Zaragoza)», CESBOR V, Borja, 1980, p. 119 y ss; J. L. Royo, »El Convento, Mallén», Arqueología 92, Zaragoza, 1992, pp. 242-244; J. L. Royo, M.A. Díaz Sanz y M.J. Dueñas, «Informe de las excavaciones arqueológicas realizadas en El Convento de Mallén, mediante convenio INEM-DGA, en 1987 », AA 1986-1987, Zaragoza, 1991, p. 437 y ss.; J. L. Royo, M.L. de Sus y F. Maneros,» Excavaciones arqueológicas en El Convento de Mallén (Zaragoza). Campaña de 1989», A.A. 1988-1989, Zaragoza, 1991, p. 523 y ss; J. A. Asensio Esteban, La ciudad en el mundo prerromano en Aragón, Zaragoza, 1995, pp. 230-235.

${ }^{36}$ Apiano (ib. 329) dice que cuando Q. Pompeyo Aulo en el 141 a. C. abandonó la Meseta en dirección al Valle del Ebro, sometió la ciudad celtíbera de Malia-Manlia. El mismo episodio es narrado por Diodoro $(33,17,1-3)$, pero la ciudad mencionada por este autor es Lagni, razón por la cual algunos investigadores la equiparan a Malia. Desde hace tiempo, se identificó Malia con Mallén, por razones homofónicas. Ver al respecto M. Beltrán, «Notas arqueológicas sobre Gallur y la comarca de las Cinco Villas de Aragón», Caesaraugusta 33-34, Zaragoza, 1970, pp. 99-100. Indudablemente las tierras de Mallén-Cortes-Novillas componen un zona muy rica y apropiada para la existencia de una posible ciudad. Los materiales arqueológicos encontrados en ellas son abundantes. Pero también hay que tener en cuenta que Mallén se considera, en razón a las distancias de los itinerarios, sede de la mansio Balsione-BeIlisone. Esto, lógicamente, representa una dificultad adicional a la suposición de una evolución directa de Malia a Mallén, pues en esa secuencia sería preciso intercalar un nombre de ciudad distinto o el de su mansio. 
Corella ${ }^{37}$. De esas tierras suponen que procedía la amplia masa trabajadora que compone los Bacadae Aracellitani que fueron combatidos y derrotados por el magister utriusque militiae Merobaudes, según relata Hidacio (Chron. 141).

La cuestión es compleja y enrevesada. Ciertamente, entre las comunidades que componen el convento cesaraugustano, Plinio (III, 3,24), sin indicar etnia de pertenencia, menciona a unos Aracelitani de condición estipendiaria. Pero una mención tan general y tan imprecisa en lo geográfico es susceptible de que corresponda, quizás, tanto al despoblado de Araciel, que ha proporcionado abundantes materiales romanos, como a la comunidad de los Aracelitani, cuya mansio Aracaeli sitúa el Itinerario Antonino (It. Ant. 455, 3) entre Alba y Alantone, en la zona de Huarte Araquil, que hasta la fecha ha proporcionado muy pocos elementos romanos. Las dos opciones que se manejan a la hora de situar geográficamente a los Bacadae Aracellitani centran sus propuestas en dos zonas vasconas muy distantes y distintas. Cabe, por tanto, la posibilidad de que en territorio vascón coexistan dos comunidades de nombres similares, al igual que en el conventus Caesaraugustanus concurrían dos ciudades del mismo nombre: la Ergavica (Castro de Santaver, Cuenca) recogida por Plinio (III, 24) entre las ciudades de derecho latino viejo y mencionada luego por Ptolomeo (II, 6,57), y la Ergavica que Ptolomeo $(I I, 6,66)$ considera vascona, pero cuya identificación es desconocida.

Pero si la consideración se lleva fundamentalmente a la cuestión del lugar de procedencia de los Bacadae Aracellitani hay razones que hacen sospechar que la ciudad norteña de Aracaeli carecía de la capacidad demográfica necesaria para movilizar, bajo la elocución de Bacadae Aracellitani, un contingente tan numeroso de trabajadores agrarios, que forzó la intervención armada del magister utriusque militiae, nada menos. La masiva movilización de campesinos rebeldes está más en consonancia con la situación de la zona del valle del Ebro, donde las explotaciones agrarias y el latifundismo alcanzaron un gran desarrollo en detrimento de los pequeños propietarios y de la amplia masa campesina, que se hundió en la miseria. Además, el despoblado de Araciel (Corella, Navarra) se encuentra a muy poca distancia de Turiaso (Tarazona, Zaragoza), una de las ciudades atacadas de improviso por los bagaudas, tras una rápida movilización.

De todas formas, la hipotética identificación de la sede de los Bacadae Aracellitani con el despoblado de Araciel suscita la cuestión, y también el problema, de una nueva agrupación urbana (de la que tampoco se conocería el comienzo de su arranque como tal), situada a muy poca distancia de las ciudades bien identificadas

37 El yacimiento del Montecillo ha proporcionado materiales tardíos, además de un fragmento co-

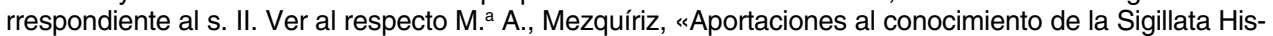
pánica», P. V. 80-81, 1960, pp. 241-273, aquí p. 270. En este trabajo también se hace referencia a los materiales de los asentamientos de Araciel y la Torrecilla de Corella. En lo que se refiere a la villa de Mélida, ver M. ${ }^{a}$ A., Mezquíriz, «Prospecciones arqueológicas en Navarra», P. V. 108-109, 1967, pp.243-264. Los materiales cerámicos obtenidos en estos asentamiento corellanos se remontan algunos de ellos al siglo I. En el asentamiento de Mélida, en concreto, estos materiales se extienden desde el s. I al IV, si bien la mayor parte de ellos pertenecen a los finales del s. II. 
de Gracchurris y Cascantum. Y este panorama comarcal urbano se complica todavía más en razón a la propuesta hipotética emitida por algunos investigadores, que sitúan la ciudad vascona de Mouskaria no muy lejos de estas ciudades.

5.1.3. Mouskaria. La ciudad de Mouskaria no acuñó monedas, ni su nombre está mencionado por ningún autor latino o griego, salvo por Ptolomeo. Tampoco aparece registrada en ninguna inscripción, ni en los Itinerarios al uso. Y esta ausencia de los Itinerarios sorprende, especialmente, si se tiene en cuenta la identificación hipotética que se hace de Mouskaria con el despoblado de Mosquera (Mosqueruela o Mosquerola). Este despoblado se halla situado en la orilla derecha del Ebro, entre Tudela y Fontellas, una zona atravesada por la ruta que marchaba a lo largo del Ebro. Esta vía de Asturica a Tarraco tenía un único recorrido hasta Gracchurris, en donde se bifurcarían en dos tramos de 161 y 179 millas respectivamente: uno pasaba por Cascante, y el otro, a lo que parece, por tierras tudelanas de la orilla derecha del Ebro hasta llegar a Mallén. En esta localidad se juntaban ambos ramales para seguir hasta Zaragoza con un único recorrido ${ }^{38}$. En ninguno de estos tramos se halla registrada ciudad o mansio alguna con el nombre de Tutela o de Mouskaria, como cabría esperar si dichas poblaciones estuviesen situadas en la trayectoria marcada por cualquiera de esos dos ramales.

Sólo Ptolomeo en su Geographiké Hyphégesis (II, 6, 67) menciona la ciudad de Mouskaria y sólo este autor la califica de vascona. Es un dato que no desentona con el lugar de identificación propuesto, pues el despoblado de Mosquera (entre Tudela y Fontellas) pertenecía al territorio vascón. Lo cual no quiere decir que ese fuese realmente su lugar de identificación. Hay que tener en cuenta que con relación a ese lugar de identificación las mediciones de Ptolomeo presentan bastantes inconvenientes. Coloca la ciudad de Mouskaria a 14 grados y 20 minutos al Este de un meridiano 0. A su vez Gracchurris se encuentra situada a 15 grados. En otras palabras, Gracchurris, con identificación segura en las Eras de San Martín de Alfaro, quedaría situada más al Este de la zona Tudela-Fontellas, lugar sugerido para la ubicación de Mouskaria. Es evidente que la identificación de una ciudad debe cimentarse en argumentos más sólidos que las simples apariencias homofónicas o en el apoyo de datos o identificaciones de otros lugares, problemáticas de suyo, que se utilizan para realizar inferencias adicionales en la identificación de Mouskaria ${ }^{39}$. Tampoco la Arqueología ofrece una ayuda significativa al respecto.

38 El Itinerario Antoniniano en la vía Ab Asturica Tarraconense (It. Ant. 450,1-451,2) ofrece un doble recorrido: por un lado Caesaraugusta-Cascanto -Calagorra-Vareia en dirección Este-Oeste, y por otro Atiliana-Barbariana (San Martín de Berberana)- Gracchurris- Bellisone- Caesaragusta, en dirección OesteEste. Por Bellisone pasaba también la ruta que desde Tarazona llegaba a Zaragoza. La bifurcación de la ruta arriba indicada en dos ramales, uno por tierras tudelanas a Bellisone y otro por Cascante a esta misma localidad, es una propuesta que realizan A. Blázquez y C. Sánchez Albornoz, «Vías romanas de Briviesca a Pamplona y de Briviesca a Zaragoza», M.J.S.E.A., 1918 , p. 8 y 11, y que siguen varios investigadores. Para las cuestiones que plantean estos dos recorridos diferenciados, ver J. J. Sayas y M. J. Peréx, «La red viaria de época romana en Navarra», en Primer Congreso General de Historia de Navarra. Comunicaciones, Pamplona, 1986, pp. 591-595.

39 Durante la segunda mitad del s. XI se expandió por la Península un compendio de las divisiones diocesanas de España, conocido por los estudiosos como la Hitación de Wamba, porque se suponía que 
Los restos arqueológicos constatados no tienen significación alguna desde el punto de vista arquitectónico y urbanístico. Los objetos encontrados no van más allá de obtención de unas pocas monedas, restos de imbrices y de tegulae y fragmentos de terra sigillata ${ }^{40}$.

\subsection{Las ciudades de las tierras comarcales de la margen izquierda del Ebro}

Frente a esta zona de la orilla derecha del Ebro, caracterizada por una real y supuesta densidad de asentamientos urbanos, la parte opuesta de la margen izquierda ofrece un panorama desolador. En el amplio espacio geográfico formado en su parte meridional por la orilla izquierda del Ebro y en su parte norte por una línea imaginaria que uniese Andelos, Cara y Segia como ciudades de referencia, no se tiene identificado ningún lugar en el que se pueda situar con seguridad ninguna de las ciudades vasconas de Ptolomeo que están por identificar. Tampoco la Arqueología ha dado con un yacimiento que haya proporcionado datos significativos y de entidad suficiente que hagan pensar que en ese yacimiento se levantaba una ciudad. No han faltado, sin embargo, intentos de localización, en los que se utiliza como método de identificación los trillados elementos de referencia de las coordenadas de longitud y latitud señaladas por Ptolomeo, las indicaciones de los Itinerarios y las semejanzas homofónicas con lugares actuales.

5.2.1. Beldalin, Erguti y Beturri. La Cosmographia del Anónimo de Rávena, obra redactada probablemente en el s. VII, pero inspirada en un mapa romano antiguo remozado entre los siglos v y vI, adquiere especial significación en los casos considerados. En un pasaje del libro IV de esta obra se mencionan ${ }^{41}$, por encima

procedía de uno de los concilios celebrados por Wamba. Esta división en diócesis no aparece registrada en las Actas Conciliares, razón por la cual algunos investigadores consideran que la Hitación de Wamba es falsa; ver al respecto L. Vázquez de Parga, La División de Wamba, Madrid, 1943. Parece que un códice que recoge esta división fue utilizado en el 1088 en un concilio celebrado en Husillos (cerca de Palencia). En este concilio se discutieron los límites de las diócesis de Osma y de Oca.

Según la Hitación de Wamba, la diócesis de Pamplona iba desde Cobello hasta Mustella y desde Loga hasta Talla; la diócesis de Tarazona, desde Mustella hasta Nampia y desde Sparga hasta Ostaual; la diócesis de Calahorra, desde Nampia hasta Sparga y desde Mustella hasta Lacala. Mustella se registra, por tanto, como un mojón común de las diócesis de Pamplona, Tarazona y Calahorra. Esta Mustella, cuya localización no se puede establecer, entra como un elemento más en la serie de identificaciones gratuitas: Mustella se correspondería con Mosquera - en una poco probable evolución fonética- y Mouskaria con Mosquera. Ver M. Álamo, «Diocése de Calahorra et la calzada» Dict. d'Hist. et de Geogr.. Eccl. , XI, col. 290. Son varios los historiadores que suponen, siguiendo en esto a A. Schulten y P. Bosch Gimpera, que Mouskaria se hallaba situada, probablemente, en el despoblado de Mosquera. Ver A. Schulten, «Las referencias sobre los Vascones hasta el año 810 después de J. C.», R.I.E.V. XVIII, 1927, reeditado en el 1971, p. 231; P. Bosch Gimpera, "Los celtas y el País Vascos», R.I.E.V. XXIII, 1932, p. 4, nota 1.

40 Sobre estos materiales, ver Excavaciones en Navarra I, 1942-1946, p. 120; B. Taracena y L. Vázquez de Parga, «La «villa» romana del Ramalete (término de Tudela) P. V. 24, 1946, en Excavaciones de Navarra II, 1947-1951.

41 El pasaje indicado del Anónimo de Rávena (IV, 43 (312,1-3) es el siguiente: Iterum iuxta super scriptam civitatem Gracuse dicitur civitas 1. Beldalin, 2. Erguti, 3. Beturri. No sabemos sin la secuencia de 
de Gracchurris, tres ciudades, Beldalin, Erguti y Beturri, situadas posiblemente a lo largo de una vía que llegaba, partiendo de Gracchurris, a una ciudad no señalada en la Cosmographia. Unos suponen que el lugar de destino de esta vía era Pompaelo; otros piensan que se trataba de la vía Gracuse-Virovesca. Un trayecto en dirección opuesta Gracchurris-Balsio (Mallén) —de encaje muy difícil, pues obligaría, necesariamente, a situar las localizaciones de Erguti y Beturri-, sería resultado de la supuesta identificación de Beldalin con Belisone (variante de Balsione), al considerarse al primero como un nombre corrupto del segundo ${ }^{42}$.

Algunos investigadores, basados en razones homofónicas, suponen que los topónimos Beturri y Erguti del Anónimo de Rávena son formas evolucionadas de las ciudades Bitouris y Ergaouía (Ergavica) de Ptolomeo. Pero tanto las unas como las otras, sean las mismas o diferentes, son ciudades que no tienen localizaciones seguras. Esto no ha impedido que se hayan realizado nuevos intentos para proponer nuevas identificaciones fundamentadas, basicamente, en criterios lingüísticos y en la aplicación cartográfica de las mediciones de Ptolomeo ${ }^{43}$. Para Erguti, por ejemplo, se propone su identificación con Arguedas (Navarra), pues se supone que se produce una evolución fonética de Erguti en Arguedas, aunque se advierte, justo es decirlo, que en esa evolución hay algunos aspectos lingüísticos oscuros ${ }^{44}$. La cuestión de la hipotética identificación de Erguti con Arguedas se complica todavía más cuando J. Untermann, basándose también en razones lingüísticas, considera que la ceca arekorata coincide con la posible forma primitiva del topónimo actual de Arguedas $^{45}$. Es evidente que el mismo topónimo no puede ser resultado de dos realidades fonéticamente distintas como Arekorata y Erguti. Además, en otro orden de cosas, está perfectamente comprobado y estudiado que los materiales arqueológicos y los restos constructivos exhumados en Arguedas corresponden a un poblado indígena que perdura en época romana, pero no a una ciudad.

las ciudades registradas en el párrafo anterior están enumeradas en orden ascendente o descendente. En el caso de la descripción de la vía de «Las Cinco Villas»(IV, 43=311, 8-14) se sabe que la direción seguida es ascendente. Es posible, por tanto, que la enumeración Beldalin-Erguti-Beturri siga también una dirección ascendente, creando con ello un problema adicional a las propuestas de aquellos investigadores que consideran que se trataba de la vía de Gracuse a Virovesca.

42 Ver al respecto A. Tovar, Iberische Landeskunde, Tomo 3. Tarraconensis, Baden-Baden, 1989, p. 382. A. M. ${ }^{a}$ Canto, «La tierra del toro. Ensayo de identificación de ciudades vasconas», $A E A .70,1997$, p. 53, propone una identificación hipotética en la localidad de Vergalijo.

${ }_{43}$ A. M. ${ }^{a}$ Canto, «La tierra del toro...o. c. p. 48 y p.51, propone identificar hipotéticamente Bitourís-Beturri con ¿Cirauqui?, Ergavica-Erguti con ¿Berbinzana? y Beldalin con ¿Vergalijo? Ver pp. 48, 51 y 52, respectivamente. En parecidos términos se expresa en «Una nueva imagen de Ptolomeo: hipótesis de ubicación de ciudades vasconas», en Fco. Villar y Fco. Beltrán (eds.), Pueblos, lenguas y escrituras en la Hispania prerromana, Salamanca, 1999, pp. 339-357.

44 Fco. J. Navarro, "La vía romana de Alfaro a Pamplona», III Congreso General de Historia de Navarra (20/23-9-1994), Pamplona, 1998, p 10. CD I-1-1, llama la atención sobre las dificultades lingüísticas que se aprecian en la propuesta de evolución de Ercavica en Erguti. Establece en su sustitución otra derivación fonética de Erguti en Arguedas, advirtiendo acerca de las dificultades que subyacen en esa derivación.

45 Ver al respecto, J. Untermann, «La aportación de las lenguas indoeuropeas», III Congreso General de Historia de Navarra (20/23-9-1994), Pamplona, 1998, p 10. CD I-1-1. p. 10 y nota 38, que remite al trabajo siguiente, que no hemos podido consultar, «Los testimonios antiguos de la lengua prerromana en territorio riojano", Logroño. en prensa. 
5.2.2.. Tutela. El pueblo actual de Arguedas se encuentra situado en la orilla izquierda del Ebro. A muy pocos kilómetros de allí, pero en la orilla derecha, se haIla Tudela de Navarra, considerada ciudad romana ${ }^{46}$ en razón al vocablo Tutela del que derivaría el topónimo. Tutela es una palabra de uso común que se emplea también como nombre de lugar y para designar a divinidades revestidas de funciones de custodia y tutelaje ${ }^{47}$. La propuesta de una supuesta Tutela romana con la Tudela actual se ha incorporado a un ámbito de conexiones periféricas que aumentan, injustificadamente, la complejidad de la propuesta. La supuesta ciudad romana de Tutela , guarnecida de la función semántica primaria de lugar de protección y defensa a ejercer en la frontera del Ebro, no sólo se la sitúa, sin datos probatorios, en algún lugar desconocido de la orilla izquierda del Ebro, sino que su función tutelar se pone en relación con las Bardenas Reales, convertidas en una entidad administrativa romana especial sobre la que la supuesta ciudad de Tutela ejercería determinadas funciones ${ }^{48}$. Desde esta perspectiva excesivamente hipotética en ambos casos, tanto Arguedas como Tudela se interferirían y excluirían mutuamente. En el supuesto de que hubiera existido la Tutela romana, sería altamente improbable que Arguedas fuese la ciudad de Erguti o la sede de la comunidad que acuñó moneda indígena con la leyenda Arekorata. Y viceversa, si Arguedas hubiese sido receptora de cualquiera de las comunidades señaladas para ella, una Tutela romana tan cercana sería inaceptable.

46 M. Dolç, Hispania y Marcial. Contribución al conocimiento de la España Antigua, Barcelona, 1953, pp. 214-215, dice con relación al topónimo Tutela mencionado por Marcial: «la correspondencia de Tutela con la actual Tudela de Navarra salta a la vista». Si esta identificación fuese cierta, Marcial sería el único autor antiguo que mencionaría esa ciudad, que no estaría muy lejana de su Bilbilis natal. A. Schulten, $R$. E., VII, 1608, la considera de procedencia romana y concluye que es un nombre de ciudad frecuente. Con mayor cautela A. Tovar, Iberische Landeskunde, Tomo 3. Tarraconensis...o.c. p. 416, sostiene que la Tudela de Navarra deriva de una Tutela romana no atestiguada. A. Canto, « La tierra del toro....o. c. pp. 56-58, participa de estas ideas en lo esencial. Utiliza, además, en apoyo de esta identificación, otro tipo de información de escasa validez para la cuestión de fondo.

47 El empleo del vocablo Tutela designando una divinidad romana de culto universal con funciones de amparo y protección, se constata en una inscripción de Veleia (Iruña, cerca de Vitoria), ver J. J. Sayas, Abengochea, «El fenómeno religioso en el pueblo vascón», en Euskadi ante la Historia, IPES, BilbaoSan Sebastián, 1987, p. 59. Su uso como topónimo está atestiguado en el poeta bilbilitano Marcial (4. 55, 16), quien menciona Tutela como lugar no muy alejado de la ciudad celtíbera de Bilbilis. Otros investigadores, por el contrario, niegan que la Tudela navarra tenga origen romano y hacen derivar su nombre de una *Todella medieval y cristiana, relacionada con el nombre de las reinas navarras Toda o Tota. Ver al respecto, J. Oliver Asín, «Orígenes de «Tudela», Homenaje a Don José Esteban Uranga, Pamplona, 1971, pp. 495-513. Acierta, pienso, en la cuestión de fondo. La Tudela de Navarra no fue, quizás, una ciudad romana, pero este autor, guiado quizás por un desmedido afán hipercrítico, acumula varias suposiciones que necesitarían la carga de la prueba.

48 A. Canto, «La tierra del toro...o. c. p. 57, se pronuncia de la forma siguiente: Intentaré demostrar, pues, que Tutela es romana, aunque se ubicara en tiempos en la margen frontera del Ebro, y una razón para el peculiar nombre. La autora parte de las nociones de protección y defensa que subyace en el concepto de tutela. Pero las funciones tutelares que le ayudan a suponer la existencia de un hipotético asentamiento nominado Tutela no serían de carácter militar, sino político-administrativas y relacionadas con Las Bardenas Reales, convertidas también, hipotéticamente, en una propiedad imperial. 


\title{
6. LA MARAÑA DE LOS TERRITORIOS DE LAS CIUDADES EN LA ZONA CONSIDERADA
}

\author{
6.1. La zona situada a ambas orillas del Ebro que va desde el yacimiento de
} La Custodia (Viana, Navarra) hasta el asentamiento romano de Mallén presentaba un abigarrado conjunto de ciudades pertenecientes a diversas etnias: el asentamiento romano de La Custodia (probablemente berón) identificado por algunos investigadores como la probable Varea indígena ${ }^{49}$, la lusona Turiaso y Mallia o Bel-

49 Es ya una opinión muy aceptada que las tierras de Viana (Navarra) pertenecían al territorio berón. Incluso algún investigador supone que el extenso yacimiento de La Custodia (Viana, Navarra), que ha proporcionado abundantes materiales cerámicos, fíbulas, broches de cinturón, placas con pactos de hospitalidad, monedas, etc., fuese la ciudad indígena de Vareia; ver al respecto, el interesante trabajo de J. C. Labeaga, La Custodia, Viana, Vareia de los Berones, Pamplona, 2000, p. 210 y ss. Esto es posible, pero una propuesta de este calibre necesitaría del apoyo de pruebas de mayor entidad, empezando por la realización de una extensa y seria excavación del poblado que permitiera contextualizar estratigráficamente los resultados desde el punto de vista urbanístico. Lo conocido hasta la fecha, en este sentido, no va más allá de que este yacimiento constituía un asentamiento que comprendía cuatro recintos, que debieron de contar con lienzos de murallas; ver al respecto, J. Armendáriz Martija, «El yacimiento arqueológico de La Custodia (Viana): triste trayectoria de una ciudad berona excepcional», TAN 13, Pamplona, 1998, pp. 7-39, aquí p. 19 y ss. Se desconoce, prácticamente, su planificación «urbana» y apenas se sabe algo de las formas, dimensiones y plantas de las casas; ver sobre este aspecto, A. Castiella («Estratigrafía en el poblado de la Edad del Hierro de La Custodia, Viana (Navarra» y La Edad del Hierro en Navarra y Rioja, Pamplona, 1977, p. 63 y ss.). Con tan ralos e insignificantes elementos urbanísticos (?) y constructivos, parece prematuro valorar el yacimiento de La Custodia como ciudad o como la importantísima Vareia berona mencionada en el fragmento 91 de Tito Livio (Vareiam validissimam regionis eius urbem venit) y por Estrabón (III, 4, 12: de ellos (de los berones) es ciudad Ouaría, situada en el paso -diábasis-del Ebro).

Por otra parte, el poblado de La Custodia (Viana, Navarra) se encuentra en la orilla izquierda del Ebro y la Vareia mencionada en el fragmento 91 de Tito Livio parece estarlo en la orilla derecha. Todas las ciudades mencionadas durante los preparativos del avance del ejército y durante la marcha de éste - Bursao, Cascantum, Gracchurris, Calagurris, Contrebia Leucade, Segovia- están situadas por debajo de la orilla derecha del Ebro. El ejército sertoriano avanzó por tierras de Bursao (Borja), Cascantum (Cascante), Gracchurris (Alfaro) hasta llegar a Calagurris, donde atravesó un río cercano, construyó un puente y a continuación instaló su campamento. El río que atravesó y sobre el que construyó el puente no es el Ebro, sino el Cidacos. Un puente sobre el Ebro no se levanta con la rapidez que da a entender el texto. Además, ni siquiera en momentos posteriores de gran prosperidad, las tierras calagurritanas que miran al Ebro dispusieron de un puente sobre ese río. En opinión de los arqueólogos, el acueducto de Alcanadre, que pasaba el Ebro y suministraba agua a Calagurris, se utilizaba también, a falta de un puente específico, como paso de personas. Con arreglo al relato del fragmento 91, Sertorio, tras la instalación del campamento, ordena al cuestor Marco Mario que vaya a reclutar tropas entre los arévacos y cilindones, y que luego regrese a Contrebia Leucade (Inestrillas, Logroño).A Cayo Insteyo le ordena también que reclute tropas de caballería en Segovia y en tierras vacceas, con el encargo añadido de que luego le espere en Contrebia, desde donde «la salida a territorio berón es facilísima». Mientras tanto Sertorio avanza (posiblemente desde las tierras de Calagurris, donde tenía instalado su campamento) per ager Vasconum hasta llegar a los confines de los berones. Es bastante improbable, por tanto, que la marcha del ejército sertoriano se realizase por la orilla izquierda (así en J. C. Labeaga, La Custodia, Viana ,o c. p.218). Desde Calagurris o desde Contrebia el camino más fácil y directo hacia los confines de los berones discurre por la orilla derecha. Todo el plan estratégico de Sertorio en la zona está montado, precisamente, en el control de las tierras de la orilla derecha del Ebro. Las tropas pompeyanas del sector se encuentran al otro lado del río, invernando en territorio vascón.

En otro orden de cosas, la propuesta de identificación del yacimiento de La Custodia con la Vareia prerromana se intenta apoyar con el argumento de que el número de monedas de la ceca uarakos encontradas en La Custodia y en otros lugares próximos es muy importante. Pero cuando se desciende a las cifras concretas (ver al respecto J.C. Labeaga, La Custodia, o. c. p. 135) la cuestión asume aspectos más complejos. El número de ejemplares de la ceca uarakos hallados en La Custodia se reduce a seis 
sio (sin identificación segura en Mallén) posiblemente, además de las vasconas Calagurris, Gracchurris y Cascantum. Estas ciudades, la mayoría con localizaciones precisas y el resto probables, mantienen entre sí distancias muy próximas, pero todavía razonables, si sólo estuviesen ellas en la zona. Lo que ocurre es que sobre esta zona, ya de suyo bastante congestionada, se proyectan, como ya hemos señalado, las ubicaciones hipotéticas de otras ciudades mencionadas por las diversas fuentes de información: Cournonion ${ }^{50}$, Tutela (?), Erguti-Arekorata-Arguedas (?), la ciudad de los Bacaudae Aracellitani (¿despoblado de Araciel, Corella?) y Mouskaria (¿despoblado de la Mosquera, Tudela ?).

6.1.1. Este afán desmedido de concentrar en la zona indicada un número relativamente elevado de identificaciones hipotéticas a añadir a las seguras, crea una situación extraña y poco real, pues no cabe duda que de este modo los territorios de las ciudades quedan achicados e interfiriéndose unos con otros. Sirva como muestra de esa desconcertante proximidad los casos de Gracchurris (Eras de San Martín, Alfaro), la ciudad de los Bacadae Aracellitani (posiblemente en el despoblado Araciel de Corella, Navarra, a pocos kms. de Alfaro), la supuesta Tutela (¿Tudela?, no muy lejos de las anteriores), Mouskaria (¿despoblado de la Mosquera?, entre Tudela y Fontellas, Navarra) y Cascantum (Cascante, a poca distancia de Tudela).

6.2. Con tanta ciudad en proximidad, cualquier intento de delimitar los territorios de estas ciudades, aunque sea de una forma muy general, está condenado al fracaso. Y esto es así incluso cuando se trata de separar de forma más precisa los territorios correspondientes a ciudades cercanas, pero que pertenecen a etnias distintas que concurren en la zona indicada. Así, en lo que respecta a la divisoria territorial entre los lusones celtibéricos y lo vascones, no hay seguridad, por ejemplo, si las tierras intensamente romanizadas de Tulebras (Navarra), Monteagudo ( $\mathrm{Na}-$

ases (sin figurar ningún denario), mientras que la cantidad de ases de la ceca barskunes obtenidos en ese mismo poblado se eleva a 36 -más de la mitad del total-y la de denarios a 16, el 40\%. Por eso, algunos investigadores piensan, teniendo en cuenta estos datos numismáticos, que el poblado de La Custodia pudiera ser el lugar de la ceca barskunes, alejándola de las tierras de la Navarra interior, en donde la Arqueología sólo registra pequeños asentamientos; ver para esta propuesta J.J. Cepeda, Moneda y circulación monetaria en el País Vasco durante la Antigüedad (siglos Il a. C.-V d.C., Bilbao, 1990.

50 Ptolomeo considera ciudad vascona a Cournonion. Varios investigadores, fiados en las mediciones de Ptolomeo y en razones meramente homofónicas, apuntan como lugares de identificación a la Hoya de Cornaba (a 5 kms de Los Arcos, Navarra) y al Barranco de Cornava (entre Viana y Lazagurría); ver al respecto B. Taracena, «La Romanización» en Excavaciones de Navarra I, Pamplona, 1942-46, p. 113. El padre G. de Pamplona», IV Simposio de Prehistoria Peninsular, Pamplona, 1966, p. 218, propone, con datos de mayor solidez, aparentemente, el lugar de Cornoino (al norte de Mendavia), un topónimo que designa a la población medieval de mismo nombre, que está mencionada en el año 1120 en el Becerro de Hirache. A, Canto, «La tierra del toro. o. c. pp. 49-50, fundamenta, con datos un tanto aleatorios, una propuesta de identificación con la localidad actual de Tafalla. Cournonion no tiene una identificación segura. Una inscripción hallada en Burdeos (CIL XIII, 621) recoge el nombre de una persona calificada de Hispanus y Curnoniensis. En razón al adjetivo Curnoniensis es probable que L. Hostilius Saturninus sea miembro de esta ciudad vascona, que residía, posiblemente, en la ciudad de Burdeos, dadas las frecuentes relaciones mantenidas por las poblaciones de ambas vertientes de los Pirineos occidentales. 
varra) —donde está testimoniado el nombre Arquius frecuente entre los celtíberos-, y Barillas (Navarra) pertenecían a la ciudad vascona de Cascantum o, por el contrario, formaban parte del territorio de Turiaso. Y en una situación similar se encontrarían las tierras de Cortes de Navarra, Buñuel (Navarra) y Ribaforada (Navarra) con relación al territorio de Mallén (Zaragoza) - supuesta sede de Mallia y de la mansio de Belsio, además de restos arqueológicos que se suponen que corresponden a un centro urbano - o respecto a cualquier otra ciudad cercana. Bursao (Borja, Zaragoza), por ejemplo, no queda muy lejos. Mayor incertidumbre se tendría con las tierras de Buñuel y Ribaforada, en el supuesto de que se aceptase las conjetura Tutela-Tudela y la localización de Mouskaria en el despoblado de Mosquera. Pero ambas conjeturas son poco probables y, por otra parte, la apretada cercanía resultante de esas supuestas identificaciones parece, en principio, inaceptable. Incluso la proximidad de Gracchurris (Alfaro) y del despoblado Araciel de Corella (posible sede de los bagaudas aracelitanos) se revela, aparentemente, un tanto forzada, aunque en este caso los datos literarios y los testimonios arqueológicos no sólo parece que son de más peso, sino que se ven reforzados por los cambios económicos producidos en la zona a partir de la crisis del siglo III d. C.

\section{EL PROBLEMA DEL CUÁNDO EMERGIERON ALGUNAS DE LAS CIUDADES DE LA ZONA CONSIDERADA}

La saturación de ciudades en la zona indicada no es el único problema. Erguti del Anónimo de Rávena y Cournonion y Mouskaria de Ptolomeo, por ejemplo, son ciudades de las que no sólo desconocemos su localización y la realidad territorial de la que proceden cuando se configuraron como civitates, sino los momentos en los que constituyeron como tales. De las dos últimas sabemos que existían a mediados del siglo ॥ d. C. al menos, pues Ptolomeo redactó su obra por aquellas fechas. Con la ciudad de Erguti sucedería lo mismo en el supuesto de que se identificara con la Ergaouica vascona de Ptolomeo.

7.1. Con la conquista y los inicios de la presencia romana la zona considerada sufrió profundas transformaciones. No se dispone, no obstante, de documentos literarios explícitos ni de datos arqueológicos significativos que permitan elaborar un esquema seguro de la organización política y social mantenida por los grupos de población que convergieron en la zona considerada y que, además, pertenecían a etnias diferentes. No resultaría excesivamente extraño suponer que al mismo tiempo que estaban organizados internamente conforme a criterios de carácter gentilicio, tenían una dimensión territorial puesta de manifiesto en la ocupación y control de un territorio más o menos definido, que garantizaban, manteniendo relaciones externas con otros grupos por medio de instituciones ancestrales como los pactos de hospitalidad. Pero los cierto es que hasta la fecha no hay testimonios de organizaciones de carácter gentilicio en suelo vascón. La inscripción de Rocaforte (Navarra), que parecía recoger una de esas organizaciones, ha sido objeto de una 
nueva lectura que la anula ${ }^{51}$. Es cierto que en suelo navarro, en el yacimiento de La Custodia (Viana, Navarra), aparecieron cuatro téseras de hospitalidad, con textos en lengua celtibérica, en los que algunos de los elementos lexicales registrados parecen referirse a topónimos o a unidades suprafamiliares ${ }^{52}$; pero las tierras de Viana (Navarra), por diversas razones, pertenecían, a lo que parece, al territorio de los berones, donde se registran, ciertamente, las organizaciones sociales suprafamiliares mediante los característicos genitivos de plural ${ }^{53}$.

7.1.1. Por efecto de la fuerza de los impulsos generados por la conquista, comenzaron a cambiar aquellas situaciones, distintas, posiblemente, según las comarcas, en las que la estructura económica imperante en ellas y la forma de explotación del suelo daban razón de la ordenación de territorio en un sentido determinado y de la forma de la organización social adoptadas por las comunidades que integraban esas comarcas. La forma de ocupar el territorio y la forma de organización social no eran la mismas en esas fechas en la franja norteña de Navarra que en la parte central y en la Ribera. Para esas fechas Calagurris y Cascantum eran ya comunidades autónomas que controlaban un territorio determinado y tenían capacidad político-administrativa para acuñar moneda indígena con el nombre de su ciudad. También se supone que la población que habitaba el cerrete del «Convento» de Mallén constituía una ciudad indígena. De ser así, existiría ya en la época de la conquista. Por otra parte conocemos por las fuentes que Ti. Sempronio Graco procedió en el 179 a. C. a la reorganización de la zona objeto de estudio, fundando la ciudad de Gracchurris. Y también es probable que en fechas de la conquista —o quizás mejor durante los conflictos sertorianos, como luego ve-

51 F. Escalada, («Antigüedades del Castillo de Javier y sus contornos», BRAH78, 1921, p. 458) dio a conocer este ara, que él tomó por estela funeraria. En las líneas $4-5$ leía Taial/orum. M. ${ }^{a}$ L. Albertos («La antroponimia en las inscripciones hispanorromanas del País vasco. Reflejos de la onomástica personal de época romana en los topónimos alaveses», ED 20, 1972, p. 344) y C. Castillo et alii (Inscripciones romanas del Museo de Navarra, Pamplona, 1981, n. ${ }^{29}$ ) consideraban que se trataba de un ara votiva. Leían las líneas $4-5$ como Tala(i)orum, un genitivo de plural que reflejaba la existencia de una unidad suprafamiliar. Recientemente H. Gimeno y J. Velaza («Correcciones de lectura a algunas inscripciones romanas de Navarra, «Anuari de Filología 17, D5, 1994, pp. 199-200) han proporcionado una nueva lectura: $X I I I / D M P /($.)esin(a)eo/Tai(f) an(n)/orum. Consideran que se trata de un ara funeraria y que la estructura onomástica del difunto es el nombre (. esine) y la filiación: Otai (f.). Lo que sigue es un genitivo de plural expresando la edad: an(n)/orum. De esta forma se disipaba el único testimonio en suelo vascón de una unidad suprafamiliar. Con todo, sorprende en esta lectura la disposición tan extraña que adopta el texto. EI numeral XIII, correspondiente a los años, se encuentra situado en primera línea, en la moldura, fuera del campo epigráfico, y no debajo de an(n)orum, donde era razonable que estuviese y había espacio para ello.

52 Para los elementos de las téseras de hospitalidad de La Custodia (Viana, Navarra) que pudieran referirse al nombre de una ciudad, a las unidades suprafamiliares, etc., y las diversas interpretaciones lingüísticas, ver al respecto J.C. Labeaga y J. Untermann, «Las téseras del poblado prerromano de La Custodia, Viana (Navarra). Descripción, epigrafía y lingüística», TAN 11, 1993-1994, pp. 50-53 ; J. Gorrochategui, «Los Pirineos entre Galia e Hispania: las lenguas», Veleia 12, 1995, pp. 197-199; J. Velaza, «A propósito de las téseras de hospitalidad de Viana», Valeia 6, 1989, pp. 193-197.

53 Tres inscripciones procedentes del territorio berón documentan las unidades de integración social indígena de los Attesuclo(n), Calaedico(n) y $\operatorname{Avilioc}(u m)$, designadas a través del genitivo del plural; ver M. ${ }^{a}$ C. González, «Las unidades organizativas indígenas II. Addenda et corrigenda», Veleia 11, 1994, p. 141, n. ${ }^{\circ} 41 ;$ p. 142, n. ${ }^{\circ} 73$ y p. 171. 
remos-, la comunidad de los Tarracenses que estaba situada entre Setia y Cara, muy cerca, por tanto, a la zona considerada, suscribiera un pacto de alianza con Roma $^{54}$.

7.1.2. Es un hecho puesto de manifiesto por la Arqueología que los pequeños poblados indígenas de Pompelo, Andelo y Cara se transformaron en centros urbanos a partir de los conflictos sertorianos. En esas fechas, las tropas sertorianas devastaron, en la zona considerada, las tierras de los bursaones, cascantinos y graccurritanos y saquearon sus cosechas. También sometieron a irreparable destrucción el poblado berón de La Custodia (Viana, Navarra), la supuesta Vareia indígena $^{55}$, que estaría situada, por tanto, en la orilla izquierda del Ebro, margen controlada por las tropas pompeyanas. A su vez, las tropas destruyeron, en las postrimerías de la guerra, con ultima caede et incendio, la ciudad de Calagurris, que fue repoblada de inmediato, posiblemente con gentes vasconas. $Y$ ya hemos dicho también que la comunidad de los Tarracenses suscribió, verosímilmente durante los conflictos sertorianos - tenía, por lo tanto, una existencia anterior-, un pacto de federación que la ligaba jurídicamente a los romanos. Es muy probable que la propuesta del foedus procediese de Pompeyo. Las circunstancias históricas parecen aconsejarlo. Pompeyo invernó con su ejército, frumenti causa, en territorio vascón, propiciando la transformación en centros urbanos de algunos poblados indígenas. Dio, además, su nombre a uno de esos poblados, el de Pompaelo y pudo ser el responsable, probablemente, de la elevación a estatuto municipal latino de las civitates stipendiariae de Cascantum y Gracchurris, que tanto habían su-

54 Para las diversas cuestiones relacionadas con la comunidad de los Tarracenses, ver J. J. Sayas Abengochea, «El municipio de Vasconia en el mundo antiguo» en IV Symposium. El municipio foral y actual en los territorios de Vasconia (Donostia-San Sebastián 9-XII-2004), en prensa.

55 El poblado de La Custodia (supuesta Vareia de los berones a la espera de datos más decisivos), que recibió influjos culturales romanos en fechas relativamente tempranas, sufrió intensamente los efectos devastadores de la guerra sertoriana. Pero estos efectos no acarrearon la destrucción del poblado, cuya desaparición se supone que tuvo lugar «hacia el cambio de era» o «por lo menos la seguridad de la desaparición del poblado antes de la primera mitad del s. I d. C.»(J. C. Labeaga, La Custodia...o. c. p. 52 y 58). Entre la guerra sertoriana y las fechas aproximadas indicadas median, por tanto, más de 70 años, dos generaciones de habitantes que siguieron ocupando el poblado al mismo tiempo que reordenaban y organizaban el territorio correspondiente en función de otras inquietudes. La guerra sertoriana convulsionó profundamente la zona (Calagurris sufrió sus efectos), llevando consigo, inevitablemente, la reordenación del territorio, reajustes en las formas de ocuparlo y el desarrollo urbanístico de algunos poblados, como los de Pompelo, Andelos y Cara. Alguno de los fenómenos indicados pudieron tener lugar en tierras de Viana. En los aledaños del poblado de La Custodia aparecen una serie de pequeños asentamientos agrícolas, que se sitúan cronológicamente en una banda que va desde el siglo I d. C. al IV d. C.; ver J.-G., Gorges, Les villas Hispano-romaines, París, 1979, pp. 325-326.

En el caso del yacimiento de La Custodia nos movemos en un terreno de inseguridad frecuente. La mayoría de los objetos y materiales obtenidos son producto de hallazgos casuales descontextualizados y de prospecciones superficiales, cuyas inferencias cronológicas se obtienen por comparación y contraste con otros similares de otros yacimientos bien datados estratigráficamente. Es posible que una excavación seria y extensa llegara a despejar algunas de las incógnitas que penden sobre este yacimiento. Por supuesto que sería un hallazgo importante si una futura excavación hiciera aflorar en ese yacimiento estructuras urbanísticas y construcciones de importancia. Por desgracia, lo conocido hasta ahora al respecto no acredita, en principio, la valoración del poblado como ciudad, mucho menos la ciudad más importante de la región. 
frido durante la guerra por ponerse de su lado. Dentro de este cúmulo de circunstancias que afectan de forma directa e indirecta al territorio vascón, Pompeyo pudo considerar de suma utilidad a su planteamiento táctico la conveniencia de romper la línea estratégica que formaban Osca y Calagurris, ciudades de absoluta fidelidad de Sertorio, introduciendo en medio de ellas la cuña de la comunidad federada de los Tarracenses, que se hallaban situados geográficamente entre las ciudades de Segia y Cara.

7.1.3. Saqueos, destrucciones de ciudades, transformaciones de poblados en centros urbanos, desplazamientos de gentes, repoblaciones de ciudades etc., son elementos que forman la entraña del mundo agitado y convulsionado de la guerra. En su vertiente positiva, si puede llamarse así, constituyen también las circunstancias propicias para que del caos de la guerra surgieran varias ciudades, como, por ejemplo, Cournonion y Nemantourista ${ }^{56}$, en el supuesto de que no hayan tenido un origen anterior.

Con posterioridad a esos conflictos y a las guerras civiles, reinó la pax romana, que impuso la unidad política, apoyada en instituciones estables y homogéneas, y garantizó a los habitantes de la zona objeto de estudio su plena integración en los modos de vida y en los esquemas político-administrativos romanos, corroborados por la adquisición de estatutos jurídicos elevados por la mayoría de las ciudades de la zona. El modelo en la forma de ocupar el territorio, que comienza a desarrollarse a partir de la época sertoriana e imperial, mantuvo su vigencia hasta el siglo III d. C., cuando los cambios en la estructura económica y social traen consigo su correspondiente reflejo en la ordenación del territorio y en el poblamiento. Estos cambios pudieron propiciar la configuración o un mayor desarrollo de la comunidad de los rebeldes aracelitanos en el despoblado de Araciel (Corella, Navarra), caso de que no tuvieran ya una existencia anterior.

56 Nemantourista ha sido objeto de varias propuestas de identificación altamente hipotéticas. Con escaso bagaje documental, se han elaborado algunas hipótesis, apenas adornadas con escuetas alusiones a las escurridizas y poco fiables mediciones de Ptolomeo, a coincidencias homofónicas o a insignificantes hallazgos arqueológicos, que se supone que prestan algún apoyo a la identificación propuesta. A. Tovar, Iberische Landeskunde...o.c., p. 409, cree que este topónimo pudiera ser un híbrido formado por el elemento celta Nemeton e Iturissa vasco. Recoge, además, las identificaciones que realizan K. Müller con Siresa y A. Balil, al que sigue J.M. Blázquez, con Sos del Rey Católico. Por su parte A. Canto, «La tierra del toro...... o. c., p. 49, coloca esa ciudad en San Tirso/ Oteiza, con una hipótesis elaborada, pero excesivamente artificial. 